\title{
Materials on Plant Leaf Surfaces are Deliquescent in a Variety of Environments
}

\author{
E. C. Tredenick ${ }^{\mathrm{a}}$, H. Stuart-Williams ${ }^{\mathrm{a}}$, T. G. Enge ${ }^{\mathrm{b}}$ \\ ${ }^{a}$ ARC Centre of Excellence in Translational Photosynthesis, Division of Plant Sciences, Research School of Biology, The Australian National University, \\ ${ }^{b}$ Research School of Earth Sciences, The Australian National University, Canberra, ACT 2601, Australia.
}

\begin{abstract}
Many materials on plant leaf surfaces are hygroscopic, and they impact penetration of foliar-applied agrochemicals, foliar water uptake, gas exchange and stomatal density. Few studies are available on the nature of these substances, and we quantify how hygroscopic these materials are. Water vapor sorption experiments on twelve leaf washes were conducted and analyzed with inductively coupled plasma-optical emission spectroscopy and X-ray diffraction. Oils were found in all Eucalyptus samples studied. For mangroves that excrete salt to the leaf surfaces, significant sorption occurred at high humidity of a total of $316 \mathrm{mg}(\sim 0.3 \mathrm{~mL})$ over 6-10 leaves, and fitted a Guggenheim, Anderson, and de Böer sorption isotherm. All plant materials studied were hygroscopic. Materials on the plant leaf surface can deliquesce and form an aqueous solution in a variety of environments where plants grow, including glasshouses and by the ocean, which is an important factor when considering plant-atmosphere relations.
\end{abstract}

Keywords: foliar, water use, hygroscopic, point of deliquescence, sorption, plant leaf, aerosol, adsorption isotherm

\section{Introduction}

The deposition of aerosols onto plant leaves is a common occurrence in the environment, yet its ecophysiological impacts are poorly understood. The aerosols are highly variable in composition and size ( $1 \mathrm{~nm}$ to $100 \mu \mathrm{m}[1])$. The deposition of aerosols of calcium has increased over the past decades in particular in western USA, due to mineral aerosols from dust storms, increased human activity upwind, increased aridity and wind transport[2]. The impact of aerosols deposited onto plant leaves requires further attention and few studies are available on the implications of deposited aerosols on plants in regards to plant-atmosphere relations, plant physiology and micrometeorology. Hygroscopic particles are contained in aerosols and may be deposited onto plant leaf surfaces, impacting many factors, both in experimental settings and field work. Leaf surface wetness can increase trace gas deposition and provide a trap for easily soluble compounds [3, 4]. Gas exchange experiments, stomatal apertures and distribution[5, 6], foliar water uptake[7], and foliar-applied agrochemical penetration[8] may be impacted by hygroscopic materials. In the context of foliar-applied agrochemical spray penetration, the effect of additional hygroscopic materials on the surface is significant, including changing the point of deliquescence of the applied salt $[9,10]$, total droplet evaporation time, droplet contact angle and area, and total amount of chemical penetrated $[8,11,12]$. Ionic substances are often present on plant leaves (especially in saline environments, such as mangroves[7]), in atmospheric particles and in sprinkler irrigation $[10,13]$. Hygroscopic materials can reduce the surface tension of droplets [14] and may allow stomatal penetration $[6,15,16]$.

Whether hygroscopic materials exist on plant leaves across all locations in which plants grow, what these materials are composed of, how likely these materials are to deliquesce into an aqueous solution and how much water is present, has not yet been thoroughly investigated in the literature. We aim to understand this distribution, understand the material's composition and determine how much water can sorb over a range of relative humidities. Our hypothesis is that materials on plant leaves can attract water, in a variety of environments, and in some cases with liquid water accumulating to form visible deliquescence. These considerations may be relevant even for plants grown in glasshouses and growth cabinets. The focus of this study is any substance present in situ, on the plant leaf surface, which is easily washed off and remains in solution after centrifugation, and may originate from deposited aerosols, sea spray, impurities in rain, soils and salts, or from inside the leaf due to leaching or excreted salts and oils.

The average thickness of a liquid layer present on a leaf surface due to hygroscopic particles is estimated to be approximately $1 \mu \mathrm{m}$, which is two orders of magnitude thinner than morning dewfall[16]. Particulate matter

Email address: eloise.tredenick@anu.edu.au (E. C. Tredenick) 
present on leaf surfaces can reach a similar mass to that of leaf waxes (leaf waxes being around $50 \mu \mathrm{g} \mathrm{cm}^{-2}$ ) [16, 17]. The electrical conductance, related to surface wetness, for a leaf and artificial leaf in a field, is similar at night (leaf stomata closed), while during the day (leaf stomata open) the leaf is more conductive. Stomata opening during the day play an important role in controlling leaf moisture $[16,18]$.

Foliar water uptake may be important for the plant during drought, though the mechanisms of penetration are not yet fully defined. To date, the majority of plant species have been found to have a capacity for foliar water uptake, in a study of 135 species, 124 species were capable and 11 incapable [19]. Water may be present on the leaf surface from a variety of sources including rain, dew and high humidity. Fog suppresses water loss from leaves, for example ameliorating daily water stress in a coastal redwood. A diurnal rhythm is present and older, well watered leaves take up the most water[20]. Without fog, species with high foliar water uptake are more likely to lose turgor during seasonal droughts[21].

Many mangrove species have glands in their leaves that excrete salts to the leaf surface. This can be seen on a mangrove grown in a growth cabinet, as shown in Fig. 1, where sea spray is not a possibility. Mangroves are known to rely on non-saline water to maintain productivity, although several mangrove species persist in areas where non-saline water from rain and groundwater is limited. Foliar water uptake from fog and mist may be important in these cases. Three species of mangroves growing in arid and humid environments have been shown to have a contribution from foliar water uptake of 32\% in Avicennia germinans, 26\% in Laguncularia racemosa and 16\% in Rhizophora mangle, and out of these only Avicennia germinans excretes salts onto the leaf surface. Within the same species, uptake was comparable across field and controlled environments, suggesting that uptake is not a plastic arid-zone adaptation but may be used as a supplemental water balance strategy in humid and arid neotropical mangroves[22]. Leaf water potential and reverse sap flow rate increase above the point of deliquescence (POD) (75\%RH for sodium chloride, $\mathrm{NaCl}$ ) [7], indicating that surface salts are an important consideration in foliar water uptake for mangroves. In these plants, trichomes have been shown to take up water[23] and achieving full leaf hydration requires the input of water from additional sources other than root water, such as atmospheric water [24]. Other plants living in halophilic environments, such as saltbush (Atriplex halimus) [3] excrete salt onto the leaf surface. Species with hygroscopic salts on the leaf surface will stay wet longer and may provide a convenient trap for aerosols. Species with more $\mathrm{NaCl}$ have very limited diversity of bacteria and fungi on the leaf surface as seen for example on saltbush (Atriplex halimus) and two mangroves (Avicennia germinans, Laguncularia racemosa) [3, 25], indicating that salt on plant leaves may be a defense mechanism. Thus the presence of salts on the leaves may yield multiple benefits, including improved water relations and bacterial control.

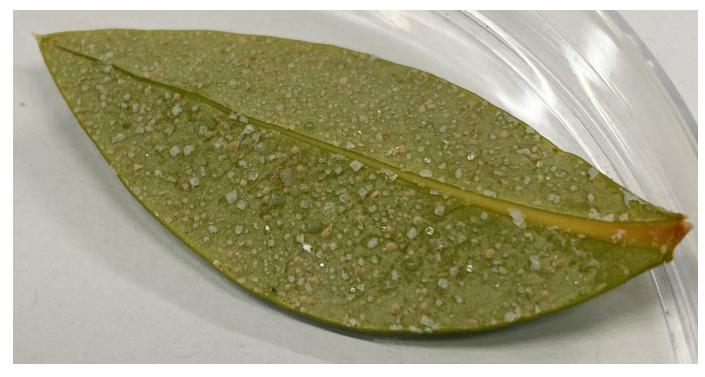

Figure 1: Naturally occurring salts visible in situ on the abaxial leaf surface of 'Cabinet mangrove' (grey/white mangrove Avicennia marina). The salts are present on the leaf due to glands that excrete salt. The leaf is visibly dry.

\subsection{Hygroscopicity and Point of Deliquescence}

Ionic substances can sorb water from the air, due to their strong attractive forces for highly polar water molecules. Calcium chloride can attract 14 times its dry weight in water at high relative humidity[26]. The ability to attract (adsorb or absorb) water molecules from the air is termed hygroscopicity. The point, in terms of relative humidity, at which a hygroscopic material can sorb sufficient quantities of water to dissolve and form an aqueous solution is called the point of deliquescence (POD) or deliquescent relative humidity (DRH). Most deliquescent materials are ionic salts and their POD can vary significantly at room temperature, from $32 \% \mathrm{RH}$ for $\mathrm{CaCl}_{2}$ [27], $75 \% \mathrm{RH}$ for $\mathrm{NaCl}$, to $97 \% \mathrm{RH}$ for $\mathrm{K}_{2} \mathrm{SO}_{4}$ [29]. If the relative humidity is above the POD, solid crystals will sorb moisture from the air until the salt dissolves and remains in solution[26, 28, 30]. The solution will continue to sorb water from the air until an equilibrium is reached between the vapor pressure of the solution and the air. $\mathrm{CaCl}_{2}$ has been found to increasingly sorb water over several hours [31]. For example, if the relative humidity of the air is $50 \% \mathrm{RH}$ and is above the POD of $\mathrm{CaCl}_{2}(32 \% \mathrm{RH})$, salt crystals or salt solution will attract water. If the relative humidity is below the 
POD, for example at $10 \% \mathrm{RH}$, the solution will continue to evaporate and eventually form crystals, with hysteresis possible. Additional to relative humidity, the rate of sorption by hygroscopic material depends on temperature, the surface area of the salt exposed to the air and the wind or air circulating over it[26]. $\mathrm{NaCl}$ crystals are seen under fluctuating relative humidities around the $\mathrm{POD}$ of $\mathrm{NaCl}$ on astomatous isolated tomato fruit cuticles, and pools of water form[32]. Small amounts of additives can significantly alter the POD of a solution, for example, surfactants, impurities and deposits on the leaf surface. Adding $1 \%$ of $\mathrm{NaCl}$ to an ammonium $\left(\mathrm{NH}_{4}^{+}\right)$solution, lowers the POD of the solution by $17 \% \mathrm{RH}$ (from $75 \% \mathrm{RH}$ to $58 \% \mathrm{RH}$ ) [10].

A mechanistic model has been developed to account for droplet evaporation including hygroscopic water absorption, the POD of the material and the ability to change the POD when adjuvants were added to the formulation[8]. Droplet evaporation is especially relevant for foliar-applied ionic agrochemicals as penetration will cease when water has evaporated. Theoretical results indicate that a high POD could be severely limiting to penetration[8]. Hygroscopic wetting can prolong droplet evaporation and penetration. Experimental and theoretical results show that at $50-70 \% \mathrm{RH}$ and $20^{\circ} \mathrm{C}$, a $1 \mu \mathrm{L}$ droplet of pure water will evaporate in $0.5-0.7$ hours on a leaf $[8,34]$, and with the inclusion of $\mathrm{CaCl}_{2}$ in the droplet, the mechanistic model shows droplet evaporation is prolonged to 9.4 hours[8].

The POD of salts is well defined in the literature, though there is less known about the sorption of salt mixtures, and salt and oil mixtures. Plant materials such as the plant cuticle, seeds and cellulose are hygroscopic[12], but generally to a lesser extent than ionic salts. Sorption at high humidity, in terms of weight increase of moisture over the dry weight in cuticles is generally around $8 \%$, cellulose $30 \%$, polar polysaccharides isolated from cuticles $49 \%$, clays (smectite) $21 \%$, while $\mathrm{CaCl}_{2}$ can sorb $1400 \%$ [12, 26, 35-38].

Heterogeneous stomatal pore area or patchy stomatal conductance may have substantial implications for photosynthetic efficiency. Plants grown in filtered or unfiltered air were compared and aerosols deposited onto the leaf from unfiltered air suppressed the heterogeneity of stomatal pore opening and response to vapor pressure deficit (VPD) [39] while increasing the minimum epidermal conductance[6], $g_{\min }$, which is a key factor of drought tolerance in plants[40]. Hygroscopic aerosols may contribute to the formation of a thin aqueous film across the leaf surface that can connect stomata to each other and the leaf interior [5, 39]. The deposited aerosols in [5] for unfiltered air were deliquescent and formed an aqueous solution at $89 \% \mathrm{RH}$, visualized with an environmental scanning electron micrograph[5]. However, only one location was investigated and the hygroscopicity of the deposits was not quantified. Salts artificially sprayed onto leaves increased the minimum epidermal conductance[40], and the electrical leaf conductance, related to leaf surface wetness, in darkness responded to changes in relative humidity close to the point of deliquescence of the salt[41].

Here we aim to find if hygroscopic materials exist on plant leaves, across all locations that plants grow. We aim to determine the materials composition, how hygroscopic they are over a large range of relative humidities and whether they deliquesce and form an aqueous solution. We focus on any substance present on the plant leaf surface, which is easily washed off and dissolved in solution, from deposited aerosols, soils and salts or from inside the leaf due to leaching or excreted salts and oils. We utilize vapor sorption methods to analyze the leaf material sorption. We analyze the leaf wash composition using powder X-ray diffraction and inductively coupled plasmaoptical emission spectroscopy (ICP-OES). We conduct vapor sorption on salt and oil mixture controls to compare our leaf wash materials to.

\section{Methods}

\subsection{Leaf Wash Sample Preparation}

Plant samples were taken at a range of distances from the ocean, with locations and species described in Table 1, and total dry weights in Table 4. The leaves were collected from the same individual plant at each location, and from the same unshaded part of the plant. All samples were collected after at least two weeks without rain and were from mature plants, unless otherwise stated. No spray applications or pre-treatments were used during the experiment.

Leaves of around the same area (6 - 10 leaves washed in total, with a total leaf area including the 2 washed leaf surfaces of approximately $\left.430 \mathrm{~cm}^{2}\right)$, enough to fill a glass container $(125 \mathrm{~mL})$ with a screw cap lid, were collected intact on their branch (so a small area of petiole was washed) and removed carefully from the plant. The leaves were placed in the bottle with $60 \mathrm{~mL}$ of de-ionized water, immediately after collection from the plant, and shaken lightly for 20 seconds[6], before the leaves were removed. The glass bottle was thoroughly cleaned beforehand, with detergent, then rinsed with de-ionized water and ethanol. The wash was centrifuged at 2,000 g for 15 minutes (Orbital 420, Clements, Australia). The centrifuging process was repeated if particles remained suspended. For 
each plant species and location, a total of two sample sets were collected from one individual plant, $120 \mathrm{~mL}$ in total; one for the vapor experiment and one for the ICP-OES experiment. The ICP-OES sample had the leaf matter removed, and was then centrifuged and dried from $60 \mathrm{~mL}$ to $5 \mathrm{~mL}$. For the vapor experiment, each $60 \mathrm{~mL}$ sample was divided equally into 3. Samples were dried in an oven for 3 days at $50^{\circ} \mathrm{C}$ and until no liquid remained. To find the initial dry weights, three empty $1.5 \mathrm{~mL}$ polypropylene Eppendorf tubes were prepared by drying them in the oven prior to use and then weighed to determine the vessel dry weights, $d w_{v}$. The wash was dried down to a smaller volume, then placed in the dry Eppendorf tube and dried further to a solid. The total dry weight of the sample and vessel was recorded, $d w_{v+s}$. The wash was centrifuged but not filtered as we wanted to investigate the insoluble particles from the leaf surface as well. Sample mass was determined for all dry weight and sorption experiments using a Mettler AT21 Comparator, Mettler Toledo, Italy, $\mathrm{d}=1 \mu \mathrm{g}, \max =22 \mathrm{~g}$.

Table 1: Sample reference, plant species and location of leaf wash samples. 6-10 leaves were collected with similar leaf area. Mature plants were collected 2 weeks after rain unless otherwise specified. Locations are in the Australian Capital Territory (ACT) or New South Wales (NSW), Australia. Collection dates between February and July 2020. Growth cabinets were contained in a large air conditioned indoor facility with 210 micron mesh air filtration, rated to P2 standards for genetically modified organism (GMO) plants.

\begin{tabular}{|c|c|c|c|c|}
\hline Reference & Common name & Scientific name & Location & Notes \\
\hline $\begin{array}{l}\text { Brackish man- } \\
\text { grove }\end{array}$ & river mangrove & $\begin{array}{l}\text { Aegiceras cornicula- } \\
\text { tum }\end{array}$ & Currowan, NSW, Aust & $\begin{array}{l}10 \mathrm{~km} \text { to ocean, edge of river, submerged } \\
\text { leaves at certain tides, excretes salt }\end{array}$ \\
\hline Cabinet mangrove & grey/white mangrove & Avicennia marina & growth cabinet & $\begin{array}{l}\text { excretes salt, not watered on leaves, } 30^{\circ} \mathrm{C} \\
\text { day } 20^{\circ} \mathrm{C} \text { night, } 60 \% \mathrm{RH} \text { day } 70 \% \mathrm{RH} \text { night, } \\
8 \text { months old }\end{array}$ \\
\hline Glasshouse chilli & birds eye or Thai chilli & Capsicum annuum & glasshouse & $\begin{array}{l}\text { not watered on leaves, } 28^{\circ} \mathrm{C} \text { day } 20^{\circ} \mathrm{C} \text { night, } \\
\text { around } 2 \text { years old }\end{array}$ \\
\hline $\begin{array}{l}\text { Ocean common } \\
\text { reed }\end{array}$ & common reed & Phragmites australis & $\begin{array}{l}\text { Surf Beach, NSW, } \\
\text { Aust }\end{array}$ & $20 \mathrm{~m}$ from beach, unlikely to be submerged \\
\hline Brackish euc & $\begin{array}{l}\text { eucalyptus grey iron- } \\
\text { bark }\end{array}$ & Eucalyptus paniculata & $\begin{array}{l}\text { same as brackish } \\
\text { mangrove }\end{array}$ & edge of river, less likely to be submerged \\
\hline Indoor peace lily & white peace lily & $\begin{array}{l}\text { Spathiphyllum } \\
\text { cochlearispathum }\end{array}$ & indoors & not watered on leaves \\
\hline Cabinet barley & barley & Hordeum vulgare & growth cabinet & as setaria \\
\hline Lake euc & $\begin{array}{l}\text { long-leaved box euca- } \\
\text { lyptus }\end{array}$ & Eucalyptus goniocalyx & Acton, ACT, Aust & $20 \mathrm{~m}$ from lake \\
\hline Euc farm & $\begin{array}{l}\text { inland scribbly gum eu- } \\
\text { calyptus }\end{array}$ & Eucalyptus rossii & Monga, NSW, Aust & $\begin{array}{l}\text { Near farms, } 10 \mathrm{~m} \text { from dirt road, } 100 \mathrm{~m} \text { from } \\
\text { highway, halfway between town and ocean }\end{array}$ \\
\hline
\end{tabular}

\subsection{Static Vapor Gravimetric Sorption Experiment - Leaf Washes}

The static vapor gravimetric sorption technique [42] was used to determine the sorption of water by the samples. Briefly, samples start out oven dry, then are successively placed in environments of increasing relative humidity to test their adsorption properties. To create a specific relative humidity, a range of salt solutions were used, being $\mathrm{MgCl}_{2}, \mathrm{Ca}\left(\mathrm{NO}_{3}\right)_{2}, \mathrm{NaCl}, \mathrm{KCl}, \mathrm{KNO}_{3}, \mathrm{~K}_{2} \mathrm{SO}_{4}$, with the equilibrium $\mathrm{RH}$ being 33.4, 55.5, 75, 84, 93 and $97 \% \mathrm{RH}$, respectively. To create these saturated salt solutions, $50 \mathrm{~mL}$ of de-ionized water was placed in a large petri dish, next to the leaf sample with the cap open, inside an air-tight larger glass vessel. The larger vessel was then stored in a temperature controlled environment for 3 days $\left(21.9^{\circ} \mathrm{C} \pm 0.4^{\circ} \mathrm{C}\right)$. At the end of 3 days, samples were quickly taken out of the large vessel, re-capped and weighed in their Eppendorf tubes to provide the wet weight of the sample, $w w_{v+s}$. It was also noted if liquid was clearly visible without the need for special equipment. Triplicates were compared and averaged. Error bars produced are the standard error of the mean. The polypropylene Eppendorf tubes can also sorb moisture, and each sample was held in a different Eppendorf tube. The wet weight of the tubes was approximated from 6 empty tubes exposed to each humidity. We focused on isothermal experiments, in order to investigate the effect of humidity on plant leaves over a large range of locations though we note that sorption can vary with temperature. 


\subsection{Salt and Oil Controls - Water Sorption Experiment}

We compare the sorption of the leaf washes for similar weights to controls based on salts and oils including mixtures. Salts and oils were weighed as shown in Table A6 and added to $1 \mathrm{~mL}$ of de-ionized water. The samples were then mixed and dissolved where possible, and dried in the oven at $50^{\circ} \mathrm{C}$ for 3 days. The same procedure was then conducted for measuring water sorption as described in the previous section. The mangrove nutrient (that the 'Cabinet mangrove' grows in a solution of), Eucalyptus oil (100\% pure) and tea tree oil (100\% pure, Melaleuca alternifolia, Australia) were purchased. The mangrove nutrient comprises mainly of $\mathrm{NaCl}, 1295 \mathrm{ppm} \mathrm{Mg}, 430 \mathrm{ppm}$ $\mathrm{Ca}$ and 390 ppm K plus micronutrients.

\subsection{X-ray Diffraction}

Powder X-ray diffraction (XRD) analysis was carried out with a Malvern Panalytical Empyrean Series 3 diffractometer, equipped with Bragg-Brentano ${ }^{\mathrm{HD}}$ divergent beam optic and a PIXcel ${ }^{3 \mathrm{D}}$ detector (1D scanning mode, $3.347^{\circ}$ active length), using $\operatorname{Co} K \alpha$ radiation. Two samples were analyzed with the leaf wash method (Table 2). Samples were analyzed with a broad beam (long-fine focus) over a range of $4-85^{\circ} 2 \theta$, with a step with of $0.0131303^{\circ}$ and scan speeds ranging from 298-2598 seconds per step depending on sample requirements. Samples were rotated horizontally to increase sampling size. Two other methods were utilized with 6 plant species; by directly studying the leaf, and its scrapings. Samples were obtained by scraping materials off the leaves (Figs. A14,A15) with a scalpel and washing any residual sample into an agate mortar with ethanol, then grinding the material with an agate pestle by hand as finely as possible. The sample was then deposited with a Pasteur pipette onto a low-background sample holder (made of Si or quartz), dried and presented to the X-ray beam without the leaf substrate. The only possible contaminant of samples prepared this way is small amounts of epicuticular wax (paraffin). Leaf wash samples (see Section 2.1, Table 2 and Figs. A12,A13) were also prepared on such low background holders. The wash samples proved somewhat sub-optimal for XRD analysis because salts readily dissolve and precipitated as potentially different compounds. The suitability of each sample for yielding instructive powder XRD data varied, depending on the sample preparation (leaf wash, leaf scraping or direct analysis of the leaf surface), the amount of material on the leaf surface, the crystal sizes (1-10 $\mu \mathrm{m}$ ideal), and leaf shape (flat better than curled for direct leaf analysis), requiring individual optimization of analytical conditions and methods for each sample. Phase identification was carried out with the software DiffracPlus Eva 10[43] and ICDD PDF-2 database[44], and quantification with Siroquant V4[45].

\subsection{ICP-OES - Inductively Coupled Plasma-optical Emission Spectroscopy}

The quantification of 70 elements was carried out using an Agilent 5110 ICP-OES (Agilent Technologies, Australia), operating in Synchronous Vertical Dual View (SVDV) mode, allowing for the simultaneous detection of axial and radial emission signals. Only concentrations for $\mathrm{Al}, \mathrm{B}, \mathrm{Ca}, \mathrm{Cu}, \mathrm{Fe}, \mathrm{K}, \mathrm{Mg}, \mathrm{Na}, \mathrm{P}, \mathrm{Si}, \mathrm{Sr}$ and $\mathrm{Zn}$ were detected above the method detection limit of $0.1 \mu \mathrm{g} / \mathrm{g}$. A double pass cyclonic spray chamber, a SeaSpray nebuliser, and a $2.4 \mathrm{~mm}$ quartz injector were used as the introduction system. Operating parameters for the ICP-OES analysis are tabulated in Table A8. All dilutions and sample preparation of samples for ICP-OES measurement were performed using ultrapure water (MilliQ, Merck), as well as sub-boiling distilled $\mathrm{HNO}_{3}$. A custom multi-element calibration solution for the elements of interest was prepared from single element standard solutions (Inorganic Ventures) and diluted to concentrations ranging from 0.1 to $20 \mu \mathrm{g} / \mathrm{mL}$. All samples were diluted and acidified to fall within the calibration curve and repeat analyses were carried out with multiple dilution steps for samples that initially exceeded the calibration range. Blank contribution was monitored by acidifying and analyzing the de-ionized water used for the wash.

\subsection{Chloride and Sulphate Presence Test}

To test for the presence of chloride $\left(\mathrm{Cl}^{-}\right)$and sulphate $\left(\mathrm{SO}_{4}{ }^{2-}\right)$, the most abundant anions in sea-water[46], $2 \mathrm{~mL}$ of liquid was removed from the $60 \mathrm{~mL}$ leaf sample washes destined for the sorption experiment. $1 \mathrm{~mL}$ aliquot of solution placed in clean $2 \mathrm{~mL}$ glass vials was used to identify chloride and sulphate non-quantitatively. For chloride, a few drops of dilute nitric acid followed by a few drops of silver nitrate $\left(\mathrm{AgNO}_{3}\right)$ in solution $(2 \%(\mathrm{w} / \mathrm{v}))$; were added to the $1 \mathrm{~mL}$ sample. A control solution of $\mathrm{CaCl}_{2}$ was used for comparison. After 10 mins the presence of a white precipitate of $\mathrm{AgCl}$ was recorded. The silver nitrate test had the unexpected effect of turning some samples brown. If the solution changed color from clear to yellow or brown tinted, it indicated that oils were present such as Eucalyptus oil, producing silver nanoparticles. $\mathrm{Ag}^{+}$is known to react with halide ions and various other compounds such as lipopolysaccharides and amino acids[47]. For the sulphate test, the same procedure was conducted but a 
few drops of barium chloride solution $(2 \%(\mathrm{w} / \mathrm{v}))$ followed after 10 minutes by a few drops of dilute hydrochloric acid and a white precipitate of $\mathrm{BaSO}_{4}$ was formed if sulphate was present.

\subsection{Moisture Gain Calculations}

To find the total $\mathrm{mg}$ and percentage increase in moisture gained for each relative humidity step over the dry weight of the sample, we need to consider the dry weight and the blank vessel water sorption. We consider

$$
\text { moisture gain }(\%)=\frac{100 \% \text { (wet weight }- \text { dry weight })}{\text { dry weight }} \text {. }
$$

We formulate $\Delta w(\%)$, the weight increase of moisture adsorbed above the dry weight of the sample (sample being the salt taken from the leaf surface) scaled with the blank, as follows:

$$
\Delta w=\frac{100 \%\left[\left(w w_{v+s}-d w_{v}-d w_{v} b /(100 \%)\right)-\left(d w_{v+s}-d w_{v}\right)\right]}{d w_{v+s}-d w_{v}}
$$

and simplifying, the final equation for $\Delta w$ becomes:

$$
\Delta w=\frac{100 \%\left(w w_{v+s}-d w_{v+s}\right)-d w_{v} b}{d w_{v+s}-d w_{v}}
$$

and the total weight of the sample in mg including the initial dry weight of the sample is:

$$
\text { Total } \mathrm{mg}=w w_{v+s}-d w_{v}(1+b /(100 \%)),
$$

where $d w_{v}(\mathrm{mg})$ is the empty vessel/ Eppendorf tube dry weight, $d w_{v+s}(\mathrm{mg})$ is the total vessel and sample dry weight, $w w_{v+s}(\mathrm{mg})$ is the total wet weight of the vessel and sample together at a given $\mathrm{RH}, b$ (\%) is the blank percentage moisture weight gain at a given $\mathrm{RH}$ and Total $\mathrm{mg}(\mathrm{mg})$ is the total weight of the sample including the sample dry weight. All parameters are direct weight measurements, except $\Delta w$, Total mg, and $b$, which are calculated. Dry weights were determined following oven drying. As Eppendorf tubes vary in weight, each tube is weighed dry and with the sample. To correct for water sorption by the polypropylene, 6 blank Eppendorf tubes were weighed with successive humidity steps, and averaged, to find $b$ using Equation (1), producing sorption between $0.033 \%$ to $0.23 \%$, at $33 \% \mathrm{RH}$ to $97 \% \mathrm{RH}$. The initial dry weight is the weight of the sample from the oven. The data point $(0,0)$ in plots of $\Delta w$, is calculated based on the dry weight, and is equivalent to $d w-d w=0$, based on Equation (3). When processing the data, if a negative value for $\Delta w$ was produced, the sample did not sorb much more than the blank, so the value for $\Delta w$ was set to zero.

\subsection{GAB isotherm}

We consider the Guggenheim, Anderson, and de Böer (GAB) isotherm[48-51] for fitting a selection of samples. The GAB isotherm describes water adsorption as a monolayer that can form multilayers at high humidities. It is formulated by applying the Langmuir isotherm to each layer (evaporation and condensation can occur only from or on exposed surfaces) and is at equilibrium where the rate of adsorption equals the rate of desorption. The GAB isotherm is as follows:

$$
\Delta w=\frac{w_{\mathrm{S}} \beta k R H}{(1-k R H)(1+k(\beta-1) R H)},
$$

where $\Delta w$ is the percentage weight increase above dry weight at each relative humidity as a percentage, $R H$ ( $R H=$ $\left.a_{w} \times 100 \%=p / p_{0} \times 100 \%\right), w_{\mathrm{S}}$ is the monolayer of water adsorbed per solid, $\beta$ is the equilibrium parameter of adsorbed water or the interaction energy between water and solid and $k$ represents the difference in free enthalpy of the water molecules in the monolayer and layers above the monolayer, where $\beta$ and $k$ depend on temperature with the Arrhenius equation and $k$ is always less than 1 . The fitting and analysis were performed using MATLAB ${ }^{\circledR}$ (Mathworks, U.S.A.). 
Table 2: XRD results for the two leaf wash samples that were expected to have the most and least amounts of materials present on the surface; 'Brackish mangrove' and 'Town euc rain'. An ' $\mathrm{x}$ ' in the table indicates that significant amounts were present, 'trace' indicates presence in small quantities. The XRD profiles are shown in Figs. A12 and A13.

\begin{tabular}{|c|c|c|c|}
\hline Minerals & Chemical composition & Brackish mangrove & Town euc rain \\
\hline quartz & $\mathrm{SiO}_{2}$ & & $\mathrm{x}$ \\
\hline plagioclase & $(\mathrm{Ca}, \mathrm{Na})_{1-2}(\mathrm{Si}, \mathrm{Al})_{2-3} \mathrm{O}_{8}$ & & $\mathrm{x}$ \\
\hline K-feldspar & $\mathrm{KAlSi}_{3} \mathrm{O}_{8}$ & & trace \\
\hline illite/muscovite & $\mathrm{KAlSi}_{3} \mathrm{O}_{10}(\mathrm{OH})_{2}$ & & $\mathrm{x}$ \\
\hline kaolinite & $\mathrm{Al}_{2} \mathrm{Si}_{2} \mathrm{O}_{5}(\mathrm{OH})_{4}$ & $\mathrm{x}$ & trace \\
\hline $\begin{array}{l}2: 1 \text { clay - chlorite, vermiculite or smec- } \\
\text { tite }\end{array}$ & & & $\mathrm{x}$ \\
\hline boehmite & $\mathrm{AlOOH}$ & & $\mathrm{x}$ \\
\hline halite & $\mathrm{NaCl}$ & $\mathrm{x}$ & \\
\hline sylvite & $\mathrm{KCl}$ & $\mathrm{x}$ & trace \\
\hline talc & $\mathrm{Mg}_{3}(\mathrm{OH})_{2} \mathrm{Si}_{4} \mathrm{O}_{10}$ & & $\mathrm{x}$ \\
\hline unidentified phase, possibly quartz & & $\mathrm{x}$ & \\
\hline
\end{tabular}

\section{Results}

To investigate what materials are on the surface of plant leaves, we use a range of techniques, with the plant species and locations described in Table 1 . We use the word "materials" due to their highly mixed nature. The total dry weights of the triplicates after centrifugation and drying are shown in Table 4, and indicate that the brackish mangrove had a large amount of material present on its leaves, $40 \mathrm{mg}$, the cabinet mangrove with appropriate scaling $41 \mathrm{mg}$, with the other sample having 3-8 $\mathrm{mg}$. The total weight of dry material is relevant in this study as increasing hygroscopic material increases the total sorption weight and our main interest is the total amount of water on the leaf. To investigate the types of materials present on the leaf, our initial analysis was performed using XRD, as shown in Table 2 and Figs. A12 and A13. 'Brackish mangrove' contained significant amounts of ionic hygroscopic compounds such as $\mathrm{NaCl}$ and $\mathrm{KCl}$, along with other minerals, while 'Town euc rain' contained trace amounts of $\mathrm{KCl}$ and mostly trace amounts of other minerals. These samples were dissolved in de-ionized water, and represent the compounds on the leaf but may not represent the original in situ configuration of the elements, for example $\mathrm{NaCl}$ and $\mathrm{K}_{2} \mathrm{SO}_{4}$ might become $\mathrm{Na}_{2} \mathrm{SO}_{4}$ and $\mathrm{KCl}$. Tests were carried out to determine what the original compounds were on the leaf and the results were similar, as shown in Figs. A14 and A15. Scrapings from the leaves gave better results than viewing the leaf directly and significant portions of wax were also present on the leaves but not quantified. XRD is unable to detect and analyze materials without a repetitive or crystalline structure that occur in very small amounts (lower detection limits for XRD range from about 0.1 to $2 \mathrm{wt}$ \% depending on compound). Therefore, ICP-OES analyses were carried out to examine the elemental composition of the samples, including trace elements.

The ICP-OES results are shown in Table 3 in $\mu \mathrm{g} / \mathrm{g}$ (ppm (parts per million)). The results indicate that the samples having significant amounts of hygroscopic salts are the 'Brackish mangrove', 'Cabinet mangrove', 'Brackish euc', 'Glasshouse chilli' and perhaps the 'Euc farm' and 'Ocean common reed', based on the determined concentration of $\mathrm{Ca}, \mathrm{Mg}$ and $\mathrm{Na}$. The 'Brackish mangrove' and 'Cabinet mangrove' have similarly large amounts of $\mathrm{Na}$, and similar amounts of the other elements. The presence of $\mathrm{Cl}^{-}$was tested using silver nitrate, indicating 'Brackish mangrove', 'Cabinet mangrove' and 'Brackish euc' contained significant amounts of $\mathrm{Cl}^{-}$, consistent with the calculated Na values. The silver nitrate test changed all 5 Eucalyptus samples brown, related to Eucalyptus oil[47], as seen in Fig. A6. 'Town euc no rain' shows the darkest color, indicating the largest amount of oil. Testing for $\mathrm{SO}_{4}{ }^{2-}$ was also

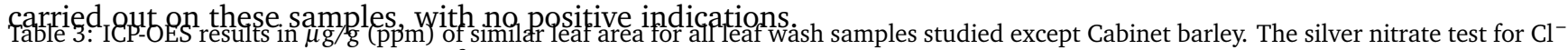
is described in Section 2.6. A test for $\mathrm{SO}_{4}{ }^{2-}$ was also carried out, with no positive indications.

\begin{tabular}{|c|c|c|c|c|c|c|c|c|c|c|c|c|c|c|}
\hline Sample & $\mathrm{Al}$ & B & $\mathrm{Ca}$ & $\mathrm{Cu}$ & $\mathrm{Fe}$ & $\mathrm{K}$ & $\mathrm{Mg}$ & Mn & $\mathrm{Na}$ & $\mathrm{P}$ & $\mathrm{Si}$ & $\mathrm{Sr}$ & $\mathrm{Zn}$ & $\mathrm{Cl}$ \\
\hline Brackish mangrove & 0.06 & 0.11 & 7.24 & 0.00 & 0.00 & 29.31 & 6.55 & 0.11 & 148.03 & 0.19 & 0.19 & 0.07 & 0.03 & $\mathrm{x}$ \\
\hline Cabinet mangrove & 0.03 & 0.16 & 9.78 & 0.06 & 0.01 & 30.20 & 4.46 & 0.04 & 199.20 & 0.15 & 0.23 & 0.03 & 0.09 & $\mathrm{x}$ \\
\hline Glasshouse chilli & 0.02 & 0.08 & 6.07 & 0.09 & 0.01 & 4.14 & 3.63 & 0.05 & 0.98 & 0.62 & 0.22 & 0.01 & 0.06 & \\
\hline Ocean common reed & 0.03 & 0.07 & 3.20 & 0.04 & 0.01 & 5.88 & 3.09 & 0.09 & 3.02 & 0.05 & 0.27 & 0.05 & 0.17 & \\
\hline Cabinet setaria & 0.01 & 0.09 & 3.91 & 0.06 & 0.00 & 13.65 & 1.30 & 0.03 & 0.55 & 0.91 & 0.02 & 0.01 & 0.03 & \\
\hline Brackish euc & 0.02 & 0.05 & 22.76 & 0.03 & 0.01 & 6.60 & 14.22 & 0.02 & 24.69 & 0.08 & 0.06 & 0.26 & 0.09 & $\mathrm{x}$ \\
\hline Indoor peace lily & 0.05 & 0.08 & 2.87 & 0.04 & 0.01 & 2.39 & 0.90 & 0.04 & 0.77 & 0.24 & 0.00 & 0.01 & 0.09 & \\
\hline Town euc rain & 0.12 & 0.06 & 1.58 & 0.08 & 0.08 & 10.38 & 1.98 & 0.08 & 0.80 & 0.24 & 0.36 & 0.00 & 0.14 & \\
\hline Town euc no rain & 0.06 & 0.02 & 1.06 & 0.00 & 0.00 & 5.30 & 0.88 & 0.05 & 0.86 & 0.58 & 0.14 & 0.00 & 0.08 & \\
\hline Lake euc & 0.09 & 0.04 & 1.35 & 0.07 & 0.04 & 5.37 & 0.91 & 0.04 & 1.32 & 0.43 & 0.19 & 0.01 & 0.07 & \\
\hline Euc farm & 0.13 & 0.05 & 1.99 & 0.04 & 0.04 & 54.90 & 1.12 & 0.33 & 2.25 & 0.25 & 0.17 & 0.01 & 0.22 & \\
\hline
\end{tabular}

The results of the water vapor sorption experiment with the leaf wash samples are shown with standard error 


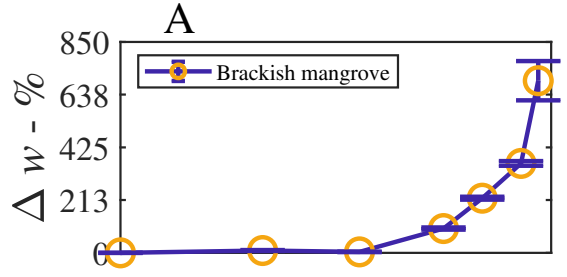

D
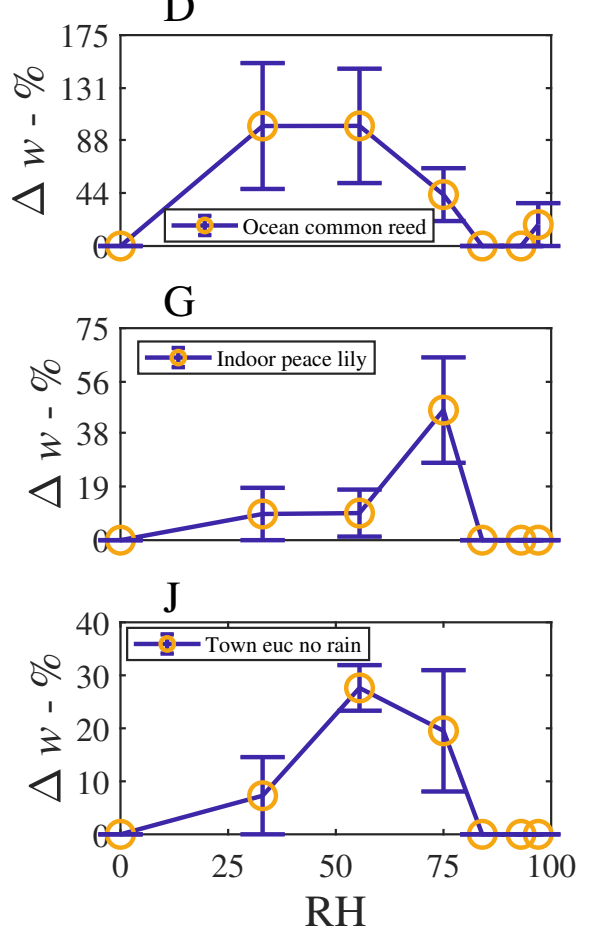
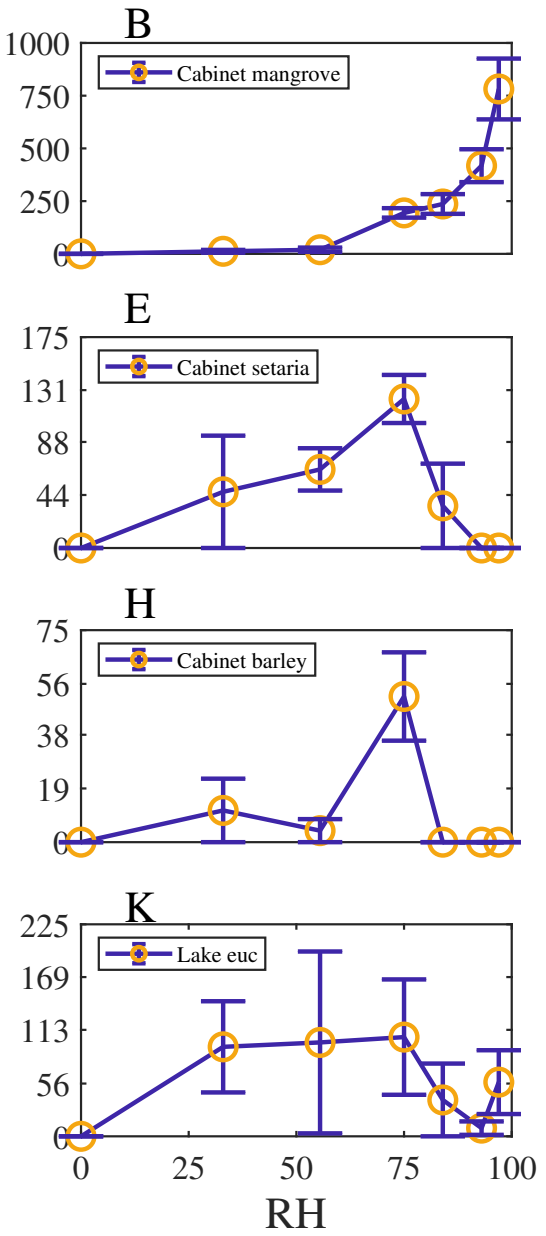
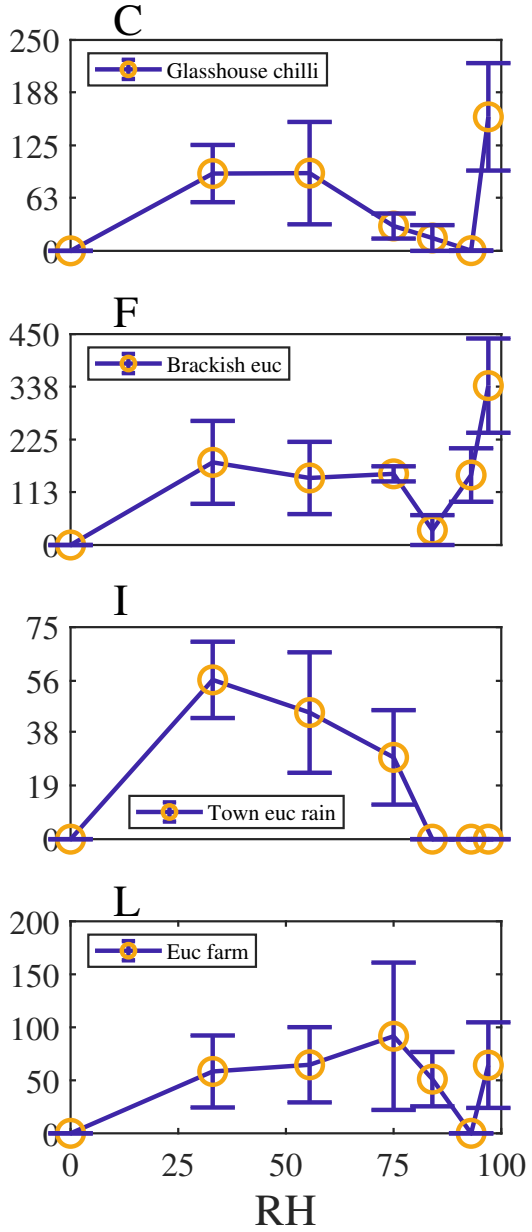

Figure 2: The percentage weight increase of moisture adsorbed above the dry weight of the leaf wash samples, $\Delta w$ - \%, vs relative humidity, RH - \%, plotted with standard error bars. Note the $x$-axis range is always the same but the $y$-axis range changes for each subfigure.

bars in Fig. 2. The percentage weight increase of moisture sorbed above the dry weight, $\Delta w$, is plotted with relative humidity, RH, as calculated in Equation (3). Significant sorption occurs at high humidities at and above 75\%RH with the 'Brackish mangrove' and 'Cabinet mangrove'. Less so but still significant sorption occurs with the 'Glasshouse chilli' and the 'Brackish euc'. All leaf washes appear to be somewhat hygroscopic. As the leaf sample washes are mixtures of different salts, minerals, oils, waxes and other materials, sorption behaves less predictably, with the exception of the mangroves with their high $\mathrm{NaCl}$ content. This is especially true above $84 \% \mathrm{RH}$ and this is discussed further around Fig. 5 in relation to the oil controls. As our focus is total water on the leaves, we consider the same data, plotted as the total of the triplicates, as total weight $(\mathrm{mg})$ with relative humidity in Fig. A7, calculated with Equation (4). We compare the strongly deliquescent leaf wash samples that produced a clearly visible aqueous solution, in Fig. 3. The 'Brackish mangrove' as expected, was the most hygroscopic and becomes visibly liquid at $75 \% \mathrm{RH}$ (POD of $\mathrm{NaCl}$ ), aided by its high initial dry weight. The 'Cabinet mangrove' also sorbed large amounts of water and became visibly wet at $75 \% \mathrm{RH}$, compatible with the dominance of $\mathrm{NaCl}$ in the coating. The 'Brackish euc' became visibly wet at $84 \% \mathrm{RH}$, and the 'Glasshouse chilli' and 'Ocean common reed' at $97 \% \mathrm{RH}$. If we compare these results to the ICP-OES data in Table 3 for the combined weight of $\mathrm{Ca}, \mathrm{Mg}$ and $\mathrm{Na}$ in $\mu \mathrm{g}$ (that are postulated to be the most hygroscopic here) in Table 4, we see the five samples that visibly deliquesce in Fig. 3 correspond well to the five highest combined masses of these cations. The highest to lowest of the sum of $\mathrm{Ca}, \mathrm{Mg}$ and $\mathrm{Na}$ also correspond reasonably well to the ranking of the maximum percentage weight increase over the dry weight, $\Delta w-\%$, in Fig. 2, which suggests that hygroscopicity of the leaf wash material may be predicted from the combined mass of $\mathrm{Ca}, \mathrm{Mg}$ and $\mathrm{Na}$ from the ICP-OES data. For the 'Brackish mangrove', the materials present significantly deliquesced, over the total sample (total of three repeats), at $97 \% \mathrm{RH}$, produced $316 \mathrm{mg}$, as shown in Figs. 3. This equates to 
0.03-0.05 mL on one leaf (assuming uniformity over 6-10 leaves), with a thickness of liquid on one leaf of 7.3 $\mu \mathrm{m}$ (14.6 $\mu \mathrm{m}$ considering salt glands are mainly on the abaxial surface of the 'Brackish mangrove'), similar but higher to estimates of $1 \mu \mathrm{m}$ using other methods with plants that do not excrete salt[16]. We note other samples were hygroscopic and could also be deliquescent but were not included in Fig. 3 as the water layer was not visible without the need for special equipment. Table 5 compares the dry weight and maximum sorption to the leaf area. The two mangrove samples produce a similar dry weight and maximum sorption.

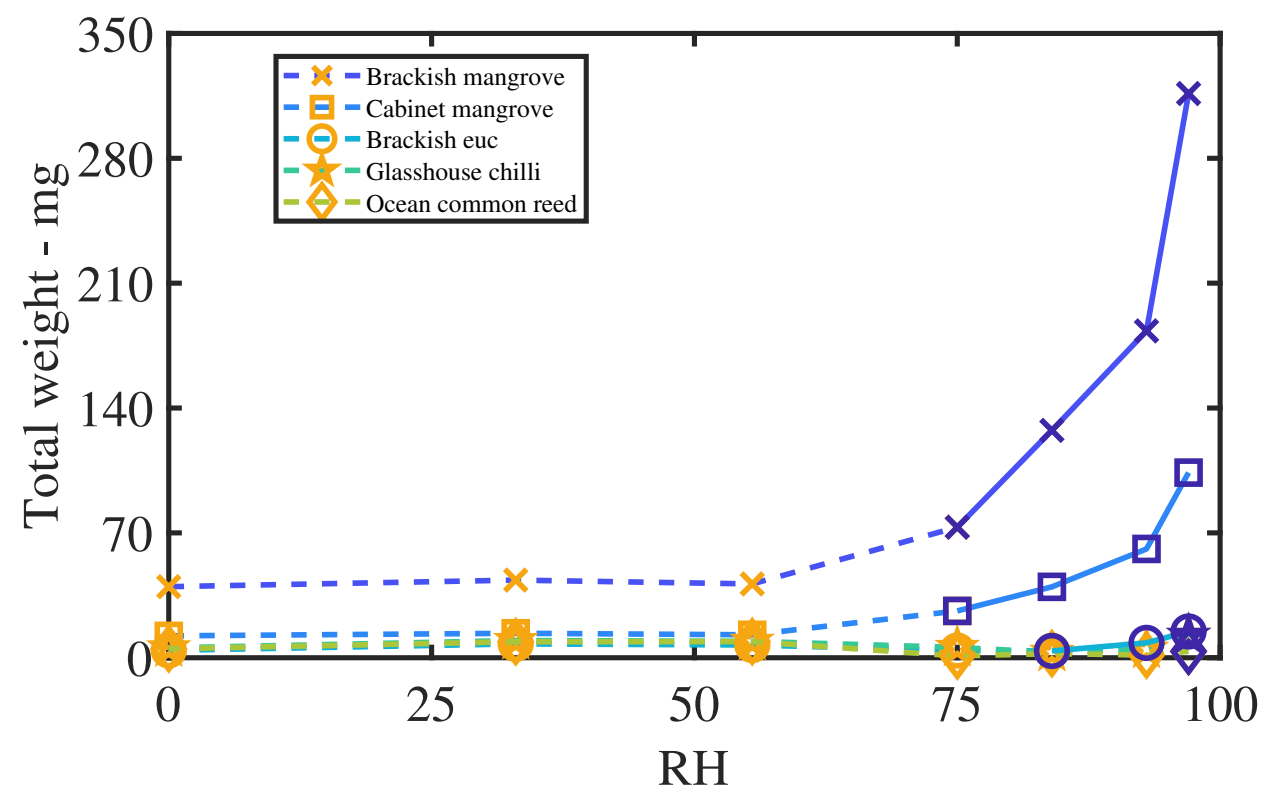

Figure 3: Samples that deliquesce visibly to the naked eye. Total weight (of three repeats with the dry weight, scaled with the blank) vs humidity (\%). The orange symbols and dashed lines indicate water is not yet visible (but may have hygroscopic growth), and the blue symbols and solid lines indicate where an aqueous solution was clearly visible. Note the significant weight of the brackish mangrove sample at $97 \% \mathrm{RH}$ of $316 \mathrm{mg}$. It is possible that other leaf samples were deliquescent, though the water was not visible to the naked eye and so were not included in this plot.

Table 4: Total dry weight of each leaf wash sample (sum of the three repeats) after oven drying and centrifuging. The maximum sorption weight percentage increase over the dry weight $\Delta w$, is compared with the combined weight in $\mu \mathrm{g}$ of the $\mathrm{Ca}, \mathrm{Mg}$ and Na ICP-OES data. The list is ordered by this combined weight: samples above the line visibly deliquesced. The combined $\mu \mathrm{g}$ of $\mathrm{Ca}, \mathrm{Mg}$ and $\mathrm{Na}$ has a positive correlation with visible deliquescence and maximum sorption. The dry weight may include some moisture that is not easily driven off and materials other than salts (such as oils, fine plant matter, waxes etc) present after centrifuging and increase the dry weight but not appear in the ICP analyses. Note the cabinet mangrove sample comprised only 3 leaves so the dry weight should be scaled accordingly for comparison with the other samples (as shown in brackets).

\begin{tabular}{llll}
\hline Sample & Total dw leaf wash - mg & Max sorption $-\Delta w-\%$ & Ca, Mg, Na $-\mu g$ \\
\hline Cabinet mangrove & $12(41)$ & 782 & 1067 \\
Brackish mangrove & 40 & 694 & 809 \\
Brackish euc & 4 & 340 & 308 \\
Glasshouse chilli & 5 & 159 & 53 \\
Ocean common reed & 5 & 100 & 47 \\
\hline Cabinet setaria & 3 & 124 & 29 \\
Euc farm & 4 & 92 & 27 \\
Indoor peace lily & 5 & 46 & 23 \\
Town euc rain & 5 & 56 & 22 \\
Lake euc & 4 & 105 & 18 \\
Town euc no rain & 8 & 28 & 14 \\
\hline
\end{tabular}

Control experiments for salt and oil sorption were conducted, for comparison to the leaf washes, to better understand whether the results were similar when salts mixtures and oils were present, as shown in Figs. A8-A11. All the controls deliquesced and formed an aqueous solution that was visible to the naked eye, except the two pure oils - Eucalyptus and tea tree. The salts and mixtures with $\mathrm{CaCl}_{2}$ generally formed liquid at $32 \% \mathrm{RH}\left(\mathrm{POD}\right.$ of $\left.\mathrm{CaCl}_{2}\right)$. Similarly mixtures with $\mathrm{NaCl}$ deliquesce at its POD of $75 \%$. The mangrove nutrient (that the 'Cabinet mangrove' 
grows in a solution of) is dominantly $\mathrm{NaCl}$, but contains other salts with a lower POD. When comparing $\mathrm{NaCl}$ plus Eucalyptus oil, to the large pure $\mathrm{NaCl}$ sample, the POD is similar, however the change in weight is less, indicating the oil was able to prevent some level of sorption but did not prevent deliquescence. When applying this outcome to the leaf wash results, it could be relevant for the 'Brackish euc', which was able to form an aqueous solution, despite the presence of some oils but to a lesser extent than the mangroves. We note that the small $\mathrm{NaCl}$ sample has higher than expected sorption at 33\%RH and this might be corrected with additional repeats.

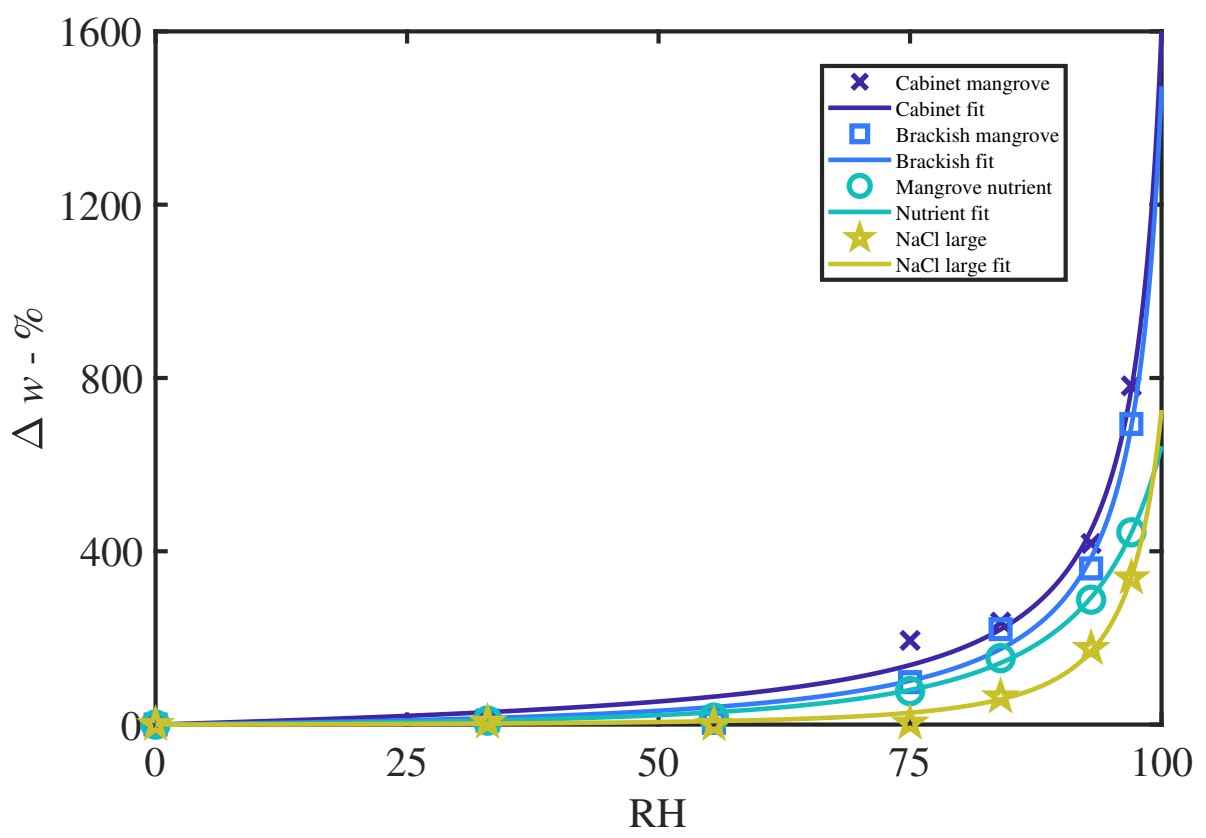

Figure 4: A selection of adsorption isotherms including cabinet and brackish mangroves, along with the controls of the mangrove nutrient and $\mathrm{NaCl}$ with a large sample size. The plot is percentage moisture gain over the dry weight vs relative humidity. The data are fitted with the GAB isotherm, as described in Equation (5). The controls were formulated with a similar dry weight to the leaf wash samples. The parameters are described in Table A7 and $\mathrm{R}^{2}$ values are greater than $98.6 \%$.

The experimental data in Fig. 4, for the 'Brackish' and 'Cabinet mangrove', compared to the mangrove nutrient and $\mathrm{NaCl}$ control, is modeled with the GAB isotherm shown in Equation (5). Fig. 4 shows that the percentage moisture gain is similar for both mangroves, the GAB isotherm has a similar trend and the percentage sorption is very similar at nearly all humidities. The sorption of the two mangrove samples compare well to the NaCl control and mangrove nutrient (mostly $\mathrm{NaCl}$ ), and therefore the sorption is likely driven largely by $\mathrm{NaCl}$. The 'Brackish' and 'Cabinet mangrove' sorption at humidities between $75-100 \% \mathrm{RH}$, is somewhat greater than the mangrove nutrient and $\mathrm{NaCl}$, which indicates that additional hygroscopic compounds are present. When comparing the percentage moisture gain to the total weight in Fig. 3, the 'Brackish mangrove' has a much greater total weight at 97\%RH but also started out with a heavier dry weight. When scaled with the dry weight, the percentage moisture gains of both mangrove samples are similar. The GAB constants have physical meaning and the values of $k$ for the four isotherms are similar, so the interaction energy between the multiple layers of water is similar. The values for $w_{s}$ are higher for the two controls, indicating that they have a larger monolayer saturation value but possibly less multilayers than the two leaf washes. In summary, the two mangroves studied from a cabinet and near brackish water, both excrete salt through the leaves, have sorption properties similar to, but greater than, $\mathrm{NaCl}$ and the mangrove nutrient, suggesting a dominance of $\mathrm{NaCl}$ but also with other hygroscopic materials.

We found a significant presence of lipophilic compounds, possibly oils or waxes. The presence of Eucalyptus oils in some leaf wash samples is indicated by the silver nitrate study, shown in Fig. A6, and waxes were found with the XRD (for example Fig. A15). In Fig. 5, as leaf washes are mixtures of salts and lipophilic compounds, the hygroscopicity of the samples is less predictable than in the controls. By comparing the Eucalyptus leaf wash samples to the Eucalyptus and tea tree oil controls, we can see that the presence of oils results in an increase of weight gain due to moisture followed by a decrease at increasingly high humidity. It is hypothesized that crystals of salts are carrying oils, which dominate the signature at low relative humidity $(\leq 75 \% \mathrm{RH})$. Once higher relative humidities are reached $(\geq 75 \% \mathrm{RH})$, then the salts start to dissociate in the liquid and dominate the observed sorption behavior. This behavior can be seen mimicked by several samples in Fig. 2. One difference to this in Fig. 5 is 'Brackish euc', 
Table 5: Dry weight per leaf area and maximum wet weight per leaf area, in $\mu \mathrm{g} \mathrm{cm}^{-2}$. The cabinet mangrove sample comprised only 3 leaves so the value in brackets from Table 4 has been utilized. The salt glands of the two mangrove species are located on the abaxial surface and as such for comparison could be scaled by 2 (as shown in brackets).

\begin{tabular}{lll}
\hline Sample & $\begin{array}{l}\mathrm{dw} \text { per leaf area } \\
\mu \mathrm{g} \mathrm{cm}^{-2}\end{array}$ & $\begin{array}{l}\text { Max sorption per leaf area } \\
\mu \mathrm{g} \mathrm{cm}^{-2}\end{array}$ \\
\hline Cabinet mangrove & $95(190)$ & $805(1609)$ \\
Brackish mangrove & $93(185)$ & $736(1471)$ \\
Brackish euc & 10 & 34 \\
Glasshouse chilli & 13 & 29 \\
Ocean common reed & 12 & 21 \\
\hline Cabinet setaria & 6 & 10 \\
Euc farm & 9 & 23 \\
Indoor peace lily & 12 & 12 \\
Town euc rain & 12 & 19 \\
Lake euc & 9 & 14 \\
Town euc no rain & 18 & 23 \\
\hline
\end{tabular}

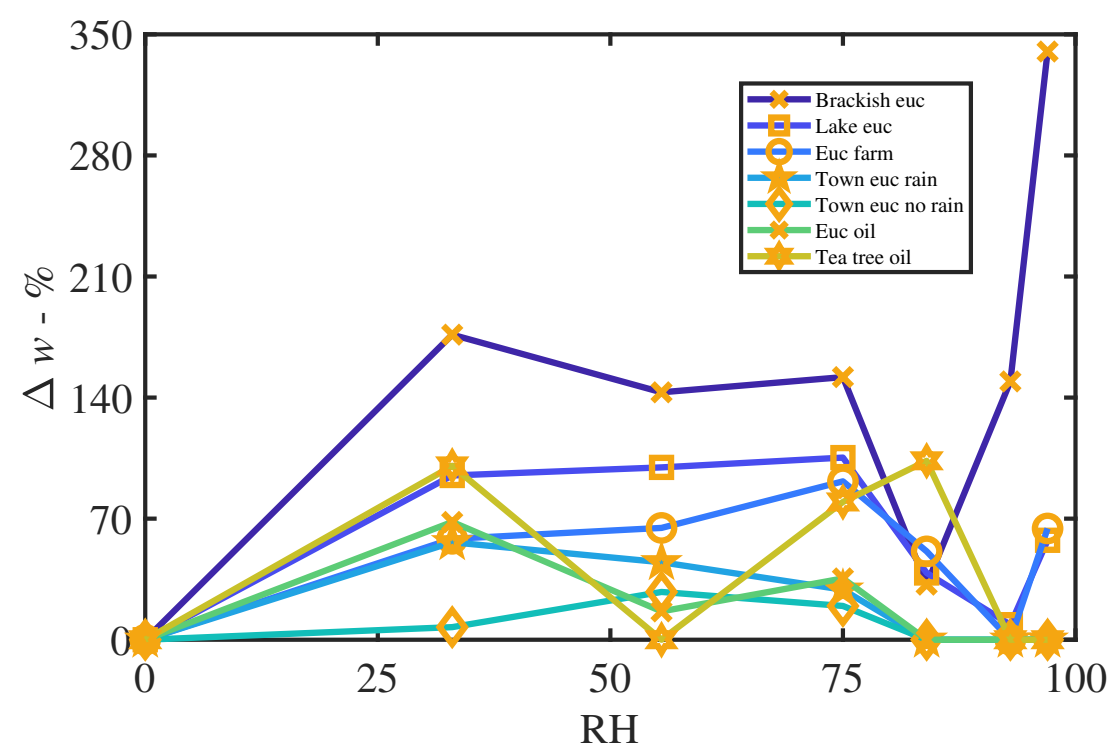

Figure 5: Percentage weight gain of moisture vs relative humidity of all Eucalyptus leaf wash samples, along with two oil controls for comparison. The oils contributed to the increasing sorption at low humidity then decrease in sorption between $33 \% \mathrm{RH}$ and $84 \% \mathrm{RH}$, while the other hygroscopic ionic compounds present in the sample contributed to weight gain at high humidities such as shown by 'Brackish euc'. The oil controls follow a similar trend to the leaf washes.

where at high humidities high sorption is possible to the point of visibly deliquescing. We observe that for this sample, the significant presence of salts as well as oils, results in the hygroscopic properties of the salts overcoming the oil after a critical mass of water is reached, the salts dissociate and high sorption occurs. The ' $\mathrm{NaCl}$ with euc oil' control sample experiment in Fig. A8 (J), indicates that this was also possible at high humidities if the amount of salt present is large enough to mask the oil effect, and the effect of the Eucalyptus oil on $\mathrm{NaCl}$ was that the maximum $\Delta w$ was reduced, compared to $\mathrm{NaCl}$ alone, in Fig. A8 (B).

\section{Discussion and Conclusions}

Materials including atmospheric aerosols on leaf surfaces substantially impact on the interaction between the leaf surface and atmospheric moisture, even for plants grown in relatively clean environments (for example growth cabinets and glasshouses). Our results, in line with other recent work [5, 39], show that not only microscopic amounts of water but relatively large volumes of water visible to the naked eye can form on plant leaf surfaces. This water can influence stomatal function and anatomy[5,39]. Our results suggest that some experimental designs may 
require the incorporation of tests, to determine if leaf washing and air filtration are necessary and if a range of relative humidities is required instead of a single humidity, depending on the research question. These considerations may be particularly important when comparing crops/field work to glasshouse/cabinet studies, agrochemical penetration experiments with foliar sprays, foliar water uptake studies and certain gas exchange experiments. We note the case of the experimental data where the material from 'Glasshouse chilli' was able to form water visible at $97 \%$ RH. This plant was two years old, did not experience any leaf washing. It is demonstrably possible that plants grown in a range of locations from glasshouses to growth cabinets may experience this phenomenon, if washing of their leaves does not occur over prolonged periods.

Outdoor plant samples and 'Glasshouse chilli' are likely to include atmospheric aerosols on their leaf surfaces. The 'Town euc rain' sample also contains impurities present in rain with larger amounts of $\mathrm{Al}, \mathrm{Cu}, \mathrm{Fe}, \mathrm{Si}$ and $\mathrm{Zn}$ present in the ICP-OES data in Table 3. 'Brackish euc' has a larger than expected amount of Ca, unexpected as the plant was adjacent to 'Brackish mangrove', which has less Ca in the ICP-OES data. The majority of the dry weight of both mangroves originates from the interior of the plant from the salt glands, though some aerosols and salt water spray exist on the 'Brackish mangrove' sample. The 'Euc farm' sample has greater levels of K, Al, Mn and Zn detected in the ICP-OES data, likely from agrochemical spray drift or particles from the nearby highway.

Hygroscopic materials on the plant leaf surface will be affected by the adjacent/local humidity. Due to the boundary layer[16], temperature and the action of stomata releasing water vapor from the interior of the leaf, the humidity on the leaf surface may be higher than the ambient relative humidity in the air. Going from air to leaf surface humidity, an increase of $35 \% \mathrm{RH}$ above the daytime ambient humidity has been found[52]. If the leaf surface humidity is greater than the ambient humidity, for example if the ambient humidity is $41 \%$ and the leaf surface humidity is at $77 \%$, then $\mathrm{NaCl}$ (POD 75\%RH) on the leaf surface will be able to deliquesce and form liquid water. Suspended or on a passive surface, such as rock, the humidity would be below the POD of NaCl and closer to the ambient humidity (of 41\%), thus the $\mathrm{NaCl}$ cannot deliquesce. When applying the boundary layer effect to sorption of salts when in situ on the plant leaf, salts will sorb moisture from the local environment even though the humidity is less than the salts POD. Therefore salts on plant leaves due to this boundary layer may form an aqueous solution at a much larger range of ambient humidities, further increasing the significance of this study. The boundary layer is relevant to plant leaves in their natural environment, but may have less importance in artificial settings, for example the cuvette of a photosynthesis system (for example Li-6400 or Li-6800) where a high fan speed is used to minimize the boundary layer thickness and in an environmental scanning electron microscope (ESEM) the vacuum conditions would minimize the boundary layer, therefore results of salts on leaves viewed with ESEM may not be influenced by this boundary layer effect.

From observations during the salt control experiments, $1 \mathrm{~g}$ of solid $\mathrm{CaCl}_{2}$ can sorb significant proportions of water and visibly deliquesce very quickly, in a matter of 5-10 mins in relatively low humidities, while it may take days to reach adsorption equilibrium, or completely dry out again in the oven (desorption). We note that in the context of hygroscopic materials on plant leaves in the environment, these adsorption and desorption timescales are very relevant as the temperature and humidity change through the day. For example, if the air humidity increases, water may be quickly adsorbed by these materials, or if the air temperature increases in the morning leading to a decrease in air humidity, hygroscopic particles on the leaf surface will extend evaporation times of residual water, and keep the leaf wet longer. These adsorption and desorption timescales for hygroscopic particles in situ on the plant leaf require further research.

The experimental data of the current work of sorption of materials on leaves, $\Delta w$, can be utilized in a mechanistic model[8] for droplet evaporation, along with additional data for the concentration of the solution at a given RH. If considering evaporation where the $\mathrm{RH}$ is changing significantly with time, over the evaporation timescale, it may be necessary to consider additional mechanisms[33] including desorption hysteresis (involving crystallization or the point of efflorescence, for example $\mathrm{NaCl}[29]$ ) of the material on the plant leaf.

Future work could include desorption, sorption data measured with time increments over a time span of longer than 3 days, conducting a similar study but looking more specifically at one location including many plant species, and individuals/biological replicates within that species. Water vapor sorption experiments could be performed on the leaf wash pellet left behind after centrifugation, which may contain insoluble waxes and mineral grains, organic debris, insect material and material sloughed from the leaf itself. This is especially relevant for the brackish mangrove sample, where the leaves had a larger amount of dried mineral dust present. The pellets were tested via XRD for the same species as in Figs. A12-A13 but no $\mathrm{NaCl}$ or other salts were found, and were not investigated further. It is however likely that some minerals, such as layered clays, sorb quite substantial quantities of water.

Initial tests were conducted to refine the leaf wash method, and several plant species were deemed unsuitable and were not used for the experiment. In particular, spongy tobacco leaves (native Australian tobacco (Nicotiana benthamiana)) that were 6 weeks of age. When shaken, tobacco stained the water green, likely with chlorophyll 
leaching from ruptured cells, so were discarded.

We designed the weights of our salt and oil mixture controls to be similar to the dry weights of materials washed from leaves. If experiments were conducted with a much larger dry weight, the sorption curves may be different. For the control experiments, we dissolved the salts in de-ionized water and then dried them in the oven, to be consistent with the method used for the leaf wash samples. For the oil controls there was significant weight loss upon oven drying and the dry sample did not sorb a large amount of additional water at high relative humidities. We note that it is uncommon for sorption isotherms of oils to be studied, and when they are studied, stabilizers are often included and sorption experiments on oils can reach equilibrium after 1-2 weeks[53], and further research is required.

Hygroscopic salts on leaves assist in maintaining leaf surface wetness when stomata are open during the day even at low humidity, maintain stomatal function and development, assist with foliar water uptake and extend the droplet evaporation time of dewfall. In terms of foliar applied agrochemicals, hygroscopic salts on the leaf either in situ or in the applied droplet formulation, can impact agrochemical penetration by altering the formulation's effectiveness at a given relative humidity, rate of droplet evaporation, penetration effectiveness of active ingredients and surface tension. Salts can also impact the experimental setup and design, and if leaves are regularly washed with water or not, especially when comparing field and glasshouse grown plants.

This work has demonstrated our aim of showing that the materials on plant leaves are hygroscopic and that an aqueous solution can form over small amounts of particles on the plant leaf surface grown in a range of environments. Five leaf washes attracted water to the point of visibly deliquescing, even in a glasshouse plant. Mangroves that excrete salt are covered with a layer that can form up to a total of $0.3 \mathrm{~mL}$ of liquid (for 6-10 leaves or $30 \mu \mathrm{L}$ on one leaf) at high humidities. This salt is mostly $\mathrm{NaCl}$, but also contains other hygroscopic particles. An unexpected outcome of our study was the higher than expected levels of oils on the surface for all Eucalyptus samples studied. As the surface properties of leaves vary a great deal, as do environmental properties, no single study can be specifically applicable to other plants and areas. Despite this, the general cases explored here have wide-reaching implications in ecological, physiological and agricultural studies.

\section{References}

[1] Lindberg, S. E., Lovett, G .M., Richter, D. D. \& Johnson, D. W. Atmospheric deposition and canopy interactions of major ions in a forest. Science 231, 141-145 (1986).

[2] Brahney, J., Ballantyne, A. P., Sievers, C. \& Neff, J. C. Increasing $\mathrm{Ca}^{2+}$ deposition in the western us: The role of mineral aerosols. Aeolian Research 10, 77-87 (2013).

[3] Simon, R. D., Abeliovich, A. \& Belkin, S. A novel terrestrial halophilic environment: the phylloplane of Atriplex halimus, a salt-excreting plant. FEMS microbiology ecology 14, 99-109 (1994).

[4] Katata, G. \& Held, A. Combined measurements of microscopic leaf wetness and dry-deposited inorganic compounds in a spruce forest. Atmospheric Pollution Research 12, 217-224 (2021).

[5] Grantz, D. A., Zinsmeister, D. \& Burkhardt, J. Ambient aerosol increases minimum leaf conductance and alters the aperture-flux relationship as stomata respond to vapor pressure deficit (vpd). New Phytologist 219, 275-286 (2018).

[6] Burkhardt, J., Zinsmeister, D., Grantz, D. A., Vidic, S., Sutton, M. A., Hunsche, M. \& Pariyar, S. Camouflaged as degraded wax: Hygroscopic aerosols contribute to leaf desiccation, tree mortality, and forest decline. Environmental Research Letters 13, 085001 (2018).

[7] Coopman, R. E., Nguyen, H. T., Mencuccini, M., Oliveira, R. S., Sack, L., Lovelock, C. E. \& Ball, M. C. Harvesting water from unsaturated atmospheres: deliquescence of salt secreted onto leaf surfaces drives reverse sap flow in a dominant arid climate mangrove, Avicennia marina. New Phytologist (2021).

[8] Tredenick, E. C., Farrell, T. W. \& Forster, W. A. Mathematical modeling of diffusion of a hydrophilic ionic fertilizer in plant cuticles: Surfactant and hygroscopic effects. Frontiers in Plant Science 9, 1888 (2018).

[9] Chen, Y. \& Lee, W. G. The effect of surfactants on the deliquescence of sodium chloride. Journal of Environmental Science and Health, Part A 36(2), 229-242 (2001). 
[10] Fernández, V., Bahamonde, H. A., Javier Peguero-Pina, J., Gil-Pelegrín, E., Sancho-Knapik, D., Gil, L., Goldbach, H. E. \& Eichert, T. Physico-chemical properties of plant cuticles and their functional and ecological significance. Journal of Experimental Botany 68, 5293-5306 (2017).

[11] Tredenick, E. C., Farrell, T. W., Forster, W. A. \& Psaltis, S. T. P. Nonlinear porous diffusion modeling of hydrophilic ionic agrochemicals in astomatous plant cuticle aqueous pores: A mechanistic approach. Frontiers in Plant Science 8, 746 URL http://journal.frontiersin.org/article/10.3389/fpls.2017.00746 (2017)

[12] Tredenick, E. C. \& Farquhar, G. D. Dynamics of moisture diffusion and adsorption in plant cuticles including the role of cellulose. Nature communications 12(1), 5042, https://doi .org/10.1038/s41467-021-25225-y (2021).

[13] Isla, R. \& Aragüés, R. Response of alfalfa (Medicago sativa L.) to diurnal and nocturnal saline sprinkler irrigations. I: Total dry matter and hay quality. Irrigation Science 27, 497-505 (2009).

[14] Dutcher, C. S., Wexler, A. S. \& Clegg, S. L. Surface tensions of inorganic multicomponent aqueous electrolyte solutions and melts. The Journal of Physical Chemistry A 114, 12216-12230 (2010).

[15] Eichert, T., Kurtz, A., Steiner, U. \& Goldbach, H. E. Size exclusion limits and lateral heterogeneity of the stomatal foliar uptake pathway for aqueous solutes and water-suspended nanoparticles. Physiologia plantarum 134, 151-160 (2008).

[16] Burkhardt, J. \& Hunsche, M. Breath figures on leaf surfaces-formation and effects of microscopic leaf wetness. Frontiers in Plant Science 4 (2013).

[17] Sæbø, A., Popek, R., Nawrot, B., Hanslin, H. M., Gawronska, H. \& Gawronski, S. W. Plant species differences in particulate matter accumulation on leaf surfaces. Science of the Total Environment 427, 347-354 (2012).

[18] Burkhardt, J. \& Gerchau, J. A new device for the study of water vapour condensation and gaseous deposition to plant surfaces and particle samples. Atmospheric Environment 28, 2012-2017 (1994).

[19] Dawson, T. E. \& Goldsmith, G. R. The value of wet leaves. New Phytologist 219, 1156-1169 (2018).

[20] Burgess, S. \& Dawson, T. The contribution of fog to the water relations of Sequoia sempervirens (D. Don): foliar uptake and prevention of dehydration. Plant, Cell \& Environment 27, 1023-1034 (2004).

[21] Eller, C. B., Lima, A. L. \& Oliveira, R. S. Cloud forest trees with higher foliar water uptake capacity and anisohydric behavior are more vulnerable to drought and climate change. New Phytologist 211, 489-501 (2016).

[22] Hayes, M. A.Chapman, S., Jesse, A., O’Brien, E., Langley, J. A., Bardou, R., Devaney, J., Parker, J. D. \& Cavanaugh, K. C., Foliar water uptake by coastal wetland plants: A novel water acquisition mechanism in arid and humid subtropical mangroves. Journal of Ecology 108, 2625-2637 (2020).

[23] Nguyen, H. T., Meir, P., Wolfe, J., Mencuccini, M. \& Ball, M. C. Plumbing the depths: Extracellular water storage in specialized leaf structures and its functional expression in a three-domain pressure-volume relationship. Plant, Cell \& Environment 40, 1021-1038 (2017).

[24] Nguyen, H. T., Meir, P., Sack, L., Evans, J. R., Oliveira, R. S. \& Ball, M. C. Leaf water storage increases with salinity and aridity in the mangrove Avicennia marina: integration of leaf structure, osmotic adjustment and access to multiple water sources. Plant, Cell \& Environment 40, 1576-1591 (2017).

[25] Gilbert, G. S., Mejía-Chang, M. \& Rojas, E. Fungal diversity and plant disease in mangrove forests: salt excretion as a possible defense mechanism. Oecologia 132, 278-285 (2002).

[26] Dow Chemical Company. Calcium Chloride Handbook. A Guide to Properties, Forms, Storage and Handling (Midland, Michigan: Dow Chemical Company., 2003).

[27] Kolthoff, I. M., Sandell, E. B., Meehan, E. \& Bruckenstein, S. Quantitative chemical analysis, vol. 826 (Macmillan London, 1969).

[28] OxyChem. Calcium Chloride Properties. http://www.oxy.com/OurBusinesses/Chemicals/Products/ Documents/CalciumChloride/173-01791.pdf (2014). 
[29] Tang, I. N., Tridico, a. C. \& Fung, K. H. Thermodynamic and optical properties of sea salt aerosols. Journal of Geophysical Research 102, 23269 (1997).

[30] Absortech. Calcium chloride: A superior choice over silica gel. http://www.absortech.jp/eng/downloads/whitepaper-silica-eng.pdf (2015).

[31] Bouzenada, S., Kaabi, A., Frainkin, L., Salmon, T. \& Léonard, A. Experimental comparative study on lithium chloride and calcium chloride desiccants. Procedia Computer Science 83, 718-725 (2016).

[32] Burkhardt, J., Basi, S., Pariyar, S. \& Hunsche, M. Stomatal penetration by aqueous solutions - an update involving leaf surface particles. New Phytologist 196, 774-787 (2012).

[33] Gregson, F. K. A., Robinson, J. F., Miles, R. E. H., Royall, C. P. \& Reid, J. P. Drying Kinetics of Salt Solution Droplets: Water Evaporation Rates and Crystallization. The Journal of Physical Chemistry B 123(1), 266-276, 10.1021/acs. jpcb.8b09584 (2019).

[34] Tredenick, E. C., Forster, W. A., Pethiyagoda, R., van Leeuwen, R. M. \& McCue, S. W. Evaporating droplets on inclined plant leaves and synthetic surfaces: Experiments and mathematical models. Journal of Colloid and Interface Science 592, 329-341 (2021).

[35] Luque, P., Gavara, R. \& Heredia, a. A study of the hydration process of isolated cuticular membranes. New phytologist 129, 283-288 (1995).

[36] Dominguez, E. \& Heredia, A. Water hydration in cutinized cell walls: a physico-chemical analysis. Biochimica et Biophysica Acta (BBA)-General Subjects 1426, 168-176 (1999).

[37] Likos, W. J. \& Lu, N. Water vapor sorption behaviour of smectite-kaolinite mixtures. Clays and Clay Minerals 50, 553-561 (2002).

[38] Belbekhouche, S., Bras, J., Siqueira, G., Chappey, C., Lebrun, L., Khelifi, B., Marais, S. \& Dufresne, A. Water sorption behavior and gas barrier properties of cellulose whiskers and microfibrils films. Carbohydrate Polymers 83, 1740-1748 (2011).

[39] Grantz, D. A., Karr, M. \& Burkhardt, J. Heterogeneity of stomatal pore area is suppressed by ambient aerosol in the homobaric species, vicia faba. Frontiers in Plant Science 11 (2020).

[40] Burkhardt, J. \& Pariyar, S. Particulate pollutants are capable to 'degrade' epicuticular waxes and to decrease the drought tolerance of Scots pine (Pinus sylvestris L.). Environmental pollution 184, 659-667 (2014).

[41] Burkhardt, J., Kaiser, H., Goldbach, H. \& Kappen, L. Measurements of electrical leaf surface conductance reveal recondensation of transpired water vapour on leaf surfaces. Plant, Cell \& Environment 22, 189-196 (1999).

[42] Ajibola, O. Desorption isotherms for plantain at several temperatures. Journal of Food Science 51, 169-171 (1986).

[43] DiffracPlus Eva software version 10.0. Bruker AXS GmbH (2004).

[44] ICDD. PDF-2. International Centre for Diffraction Data (2004).

[45] Taylor, J. Computer programs for standardless quantitative analysis of minerals using the full powder diffraction profile. Powder diffraction 6, 2-9 (1991).

[46] Bryan, C. R. \& Schindelholz, E. J. Properties of brines formed by deliquescence of sea-salt aerosols. In CORROSION 2018 (OnePetro, 2018).

[47] Pourmortazavi, S. M., Taghdiri, M., Makari, V. \& Rahimi-Nasrabadi, M. Procedure optimization for green synthesis of silver nanoparticles by aqueous extract of Eucalyptus oleosa. Spectrochimica Acta Part A: Molecular and Biomolecular Spectroscopy 136, 1249-1254 (2015).

[48] Guggenheim, E. A. Applications of statistical mechanics (1966).

[49] de Boer, J. The dynamic character of chemisorptions (1953). 
[50] Anderson, R. B. Modifications of the Brunauer, Emmett and Teller equation. Journal of the American Chemical Society 68, 686-691 (1946).

[51] Timmermann, E. O. Multilayer sorption parameters: BET or GAB values? Colloids and Surfaces A: Physicochemical and Engineering Aspects 220, 235-260 (2003).

[52] Boulard, T., Mermier, M., Fargues, J., Smits, N., Rougier, M. \& Roy, J. C. Tomato leaf boundary layer climate: implications for microbiological whitefly control in greenhouses. Agricultural and Forest Meteorology 110, 159-176 (2002).

[53] Charoen, R., Jangchud, A., Jangchud, K., Harnsilawat, T. \& McClements, D. J. The physical characterization and sorption isotherm of rice bran oil powders stabilized by food-grade biopolymers. Drying Technology 33, 479-492 (2015).

\section{Funding}

The authors acknowledge funding provided by the Australian Research Council Centre of Excellence for Translational Photosynthesis (CE1401000015).

\section{Acknowledgment}

The authors thank Ulrike Troitzsch (ANU) for conducting the XRD experiments, Brett Knowles (ANU) for assisting with the ICP-OES experiments and Graham Farquhar (ANU) for his advice and thoughtful conversations.

\section{Author contributions}

ET is responsible for project motivation, experimental design, conducting vapor sorption experiments, analysis, model fitting, results and article writing, editing and revision. HS is responsible for the experimental and biological consultation, article editing and revision. TE is responsible for conducting ICP-OES experiments and methodology, article editing and revision.

\section{Conflict of interest statement}

The authors declare that the research was conducted in the absence of any commercial or financial relationships that could be construed as a potential conflict of interest.

\section{Appendix}

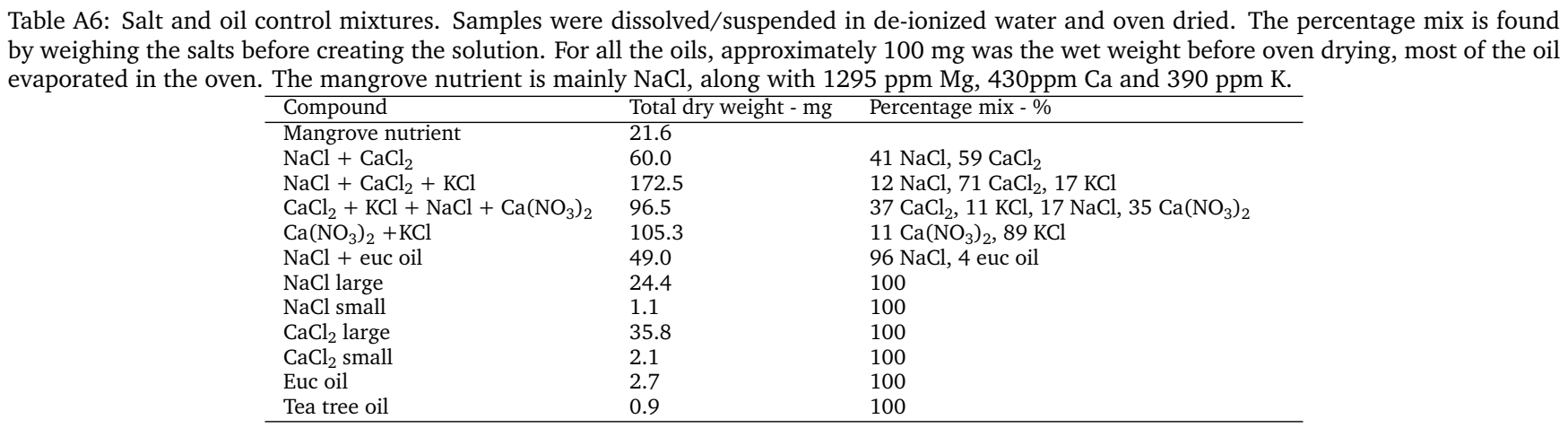


bioRxiv preprint doi: https://doi.org/10.1101/2021.11.22.469518; this version posted December 14, 2021. The copyright holder for this preprint (which was not certified by peer review) is the author/funder, who has granted bioRxiv a license to display the preprint in perpetuity. It is made available under aCC-BY-NC-ND 4.0 International license.

Table A7: GAB parameters for Figure 4, fitted with Equation (5)

\begin{tabular}{lllll}
\hline Sample & $w_{\mathrm{S}}$ & $\beta$ & $k \times 10^{-3}$ & $\mathrm{R}^{2}-\%$ \\
\hline Cabinet mangrove & 46.5 & 1.5 & 9.71 & 98.6 \\
Brackish mangrove & 43.4 & 0.64 & 9.72 & 99.0 \\
Mangrove nutrient & 162.2 & 0.098 & 8.88 & 99.8 \\
NaCl large & 424.4 & 0.0081 & 9.36 & 99.3 \\
\hline
\end{tabular}

Table A8: Operating parameters for ICP-OES measurements.

\begin{tabular}{|c|c|}
\hline Parameter & Value \\
\hline Read time & $20 \mathrm{~s}$ \\
\hline Replicates & 3 \\
\hline Sample uptake delay & $25 \mathrm{~s}$ \\
\hline Rinse time & $30 \times 2 \mathrm{~s}\left(0.5 \mathrm{M} \mathrm{HNO}_{3} \& \mathrm{MQ}\right)$ \\
\hline Stabilization time & $10 \mathrm{~s}$ \\
\hline Pump speed & $12 \mathrm{rpm}$ \\
\hline Fast pump & ON \\
\hline $\mathrm{RF}$ power & $1.5 \mathrm{~kW}$ \\
\hline Aux flow & $1.0 \mathrm{~L} \mathrm{~min}^{-1}$ \\
\hline Plasma flow & $12.0 \mathrm{~L} \mathrm{~min}^{-1}$ \\
\hline Nebulizer flow & $0.7 \mathrm{~L} \mathrm{~min}^{-1}$ \\
\hline Viewing mode & SVDV \\
\hline Viewing height & $5 \mathrm{~mm}$ \\
\hline Background correction & FACT \\
\hline Number of pixels & 2 \\
\hline Quality control & $1 \mu \mathrm{g} \mathrm{g}^{-1}$ multi element \\
\hline Analytes & $\begin{array}{l}\text { Al }(396.152 \mathrm{~nm}) ; \mathrm{B}(249.772 \mathrm{~nm}) ; \mathrm{Ca}(422.673 \mathrm{~nm}) ; \mathrm{Cu}(327.395 \mathrm{~nm}) ; \mathrm{Fe}(238.204 \mathrm{~nm}) ; \mathrm{K} \\
(766.491 \mathrm{~nm}) ; \mathrm{Mg}(279.553 \mathrm{~nm}) ; \mathrm{Mn}(257.610 \mathrm{~nm}) ; \mathrm{Na}(589.592 \mathrm{~nm}) ; \mathrm{P}(213.618 \mathrm{~nm}) ; \mathrm{Si} \\
(251.611 \mathrm{~nm}) ; \mathrm{Sr}(407.771 \mathrm{~nm}) ; \mathrm{Zn}(213.857 \mathrm{~nm})\end{array}$ \\
\hline Drift correction & C (193.027 nm); $\mathrm{Ar}(565.070 \mathrm{~nm}, 645.918 \mathrm{~nm}, 675.283 \mathrm{~nm}, 699.217 \mathrm{~nm}, 704.096 \mathrm{~nm})$ \\
\hline
\end{tabular}

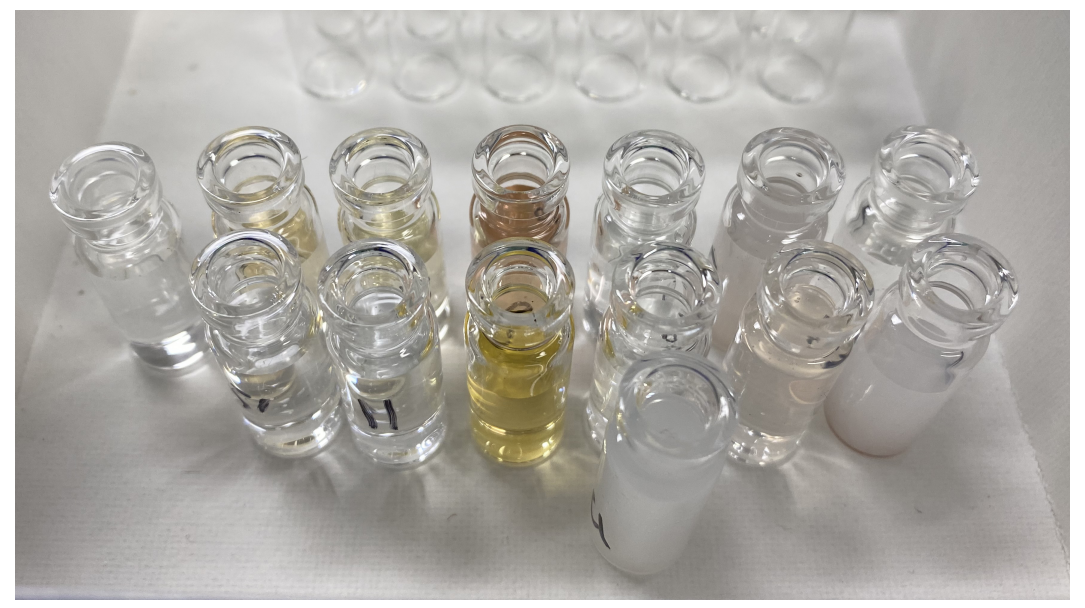

Figure A6: Silver nitrate test for the presence of $\mathrm{Cl}^{-}$. Samples that reacted formed a milky white precipitate of AgCl. These were Brackish mangrove, Brackish Eucalyptus and Cabinet mangrove. This test also showed the presence of nanoparticles related to Eucalyptus oils with a change in colour from clear of milky to yellow to brown. All 5 Eucalyptus samples changed colour. The darkest colour (copper brown) was Town euc no rain, the second was Town euc rain (dark yellow). 

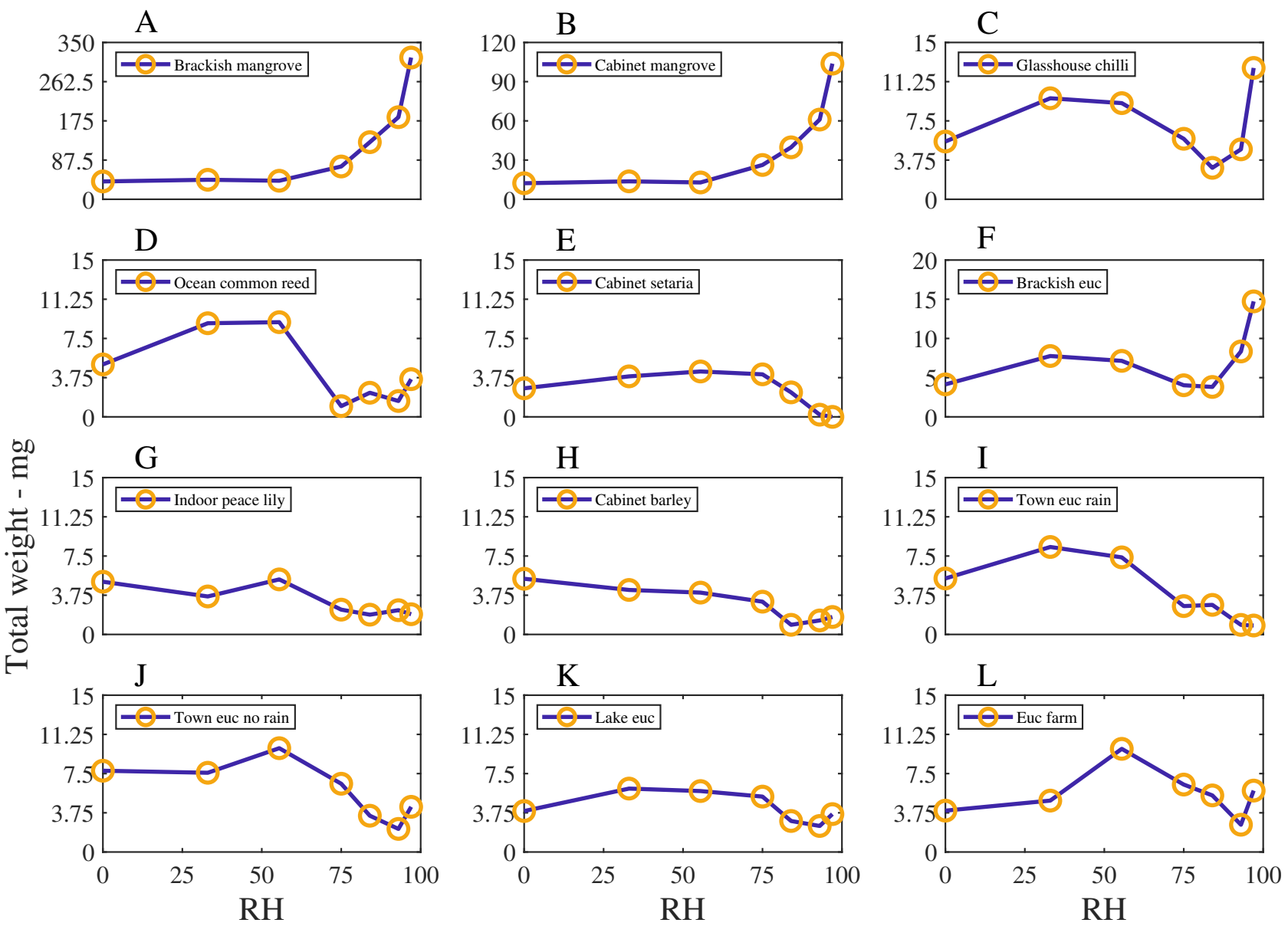

Figure A7: The Total weight (mg) of moisture adsorbed for the leaf wash samples, with relative humidity, RH (\%). Total weight includes the dry weight and is scaled with the blank. Note that the $y$-axis range changes for each subfigure. 

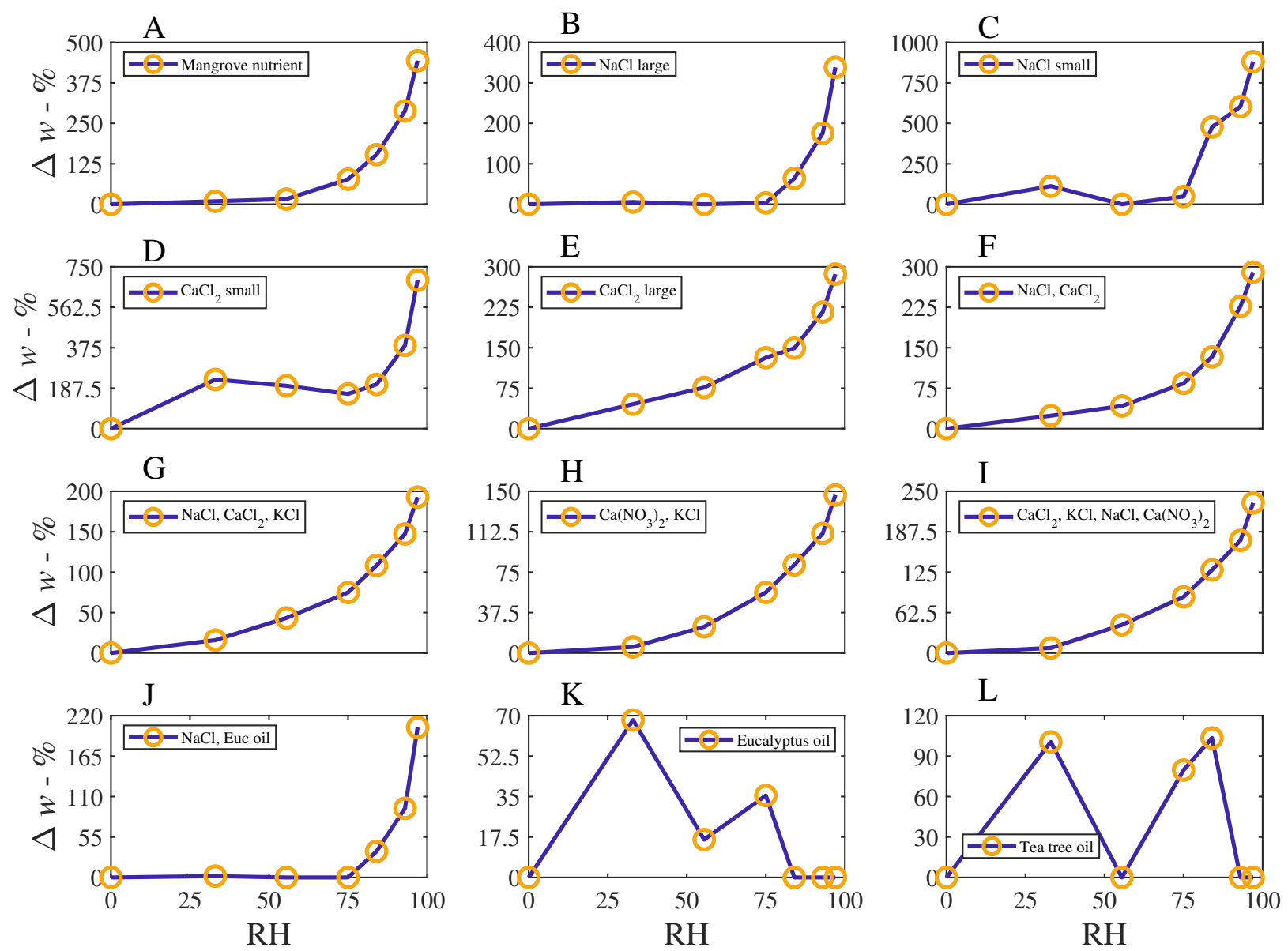

Figure A8: The percentage weight increase of moisture adsorbed above the dry weight of the controls, $\Delta w-\%$, with relative humidity, RH - \%. The $y$-axis range changes for each subfigure. 

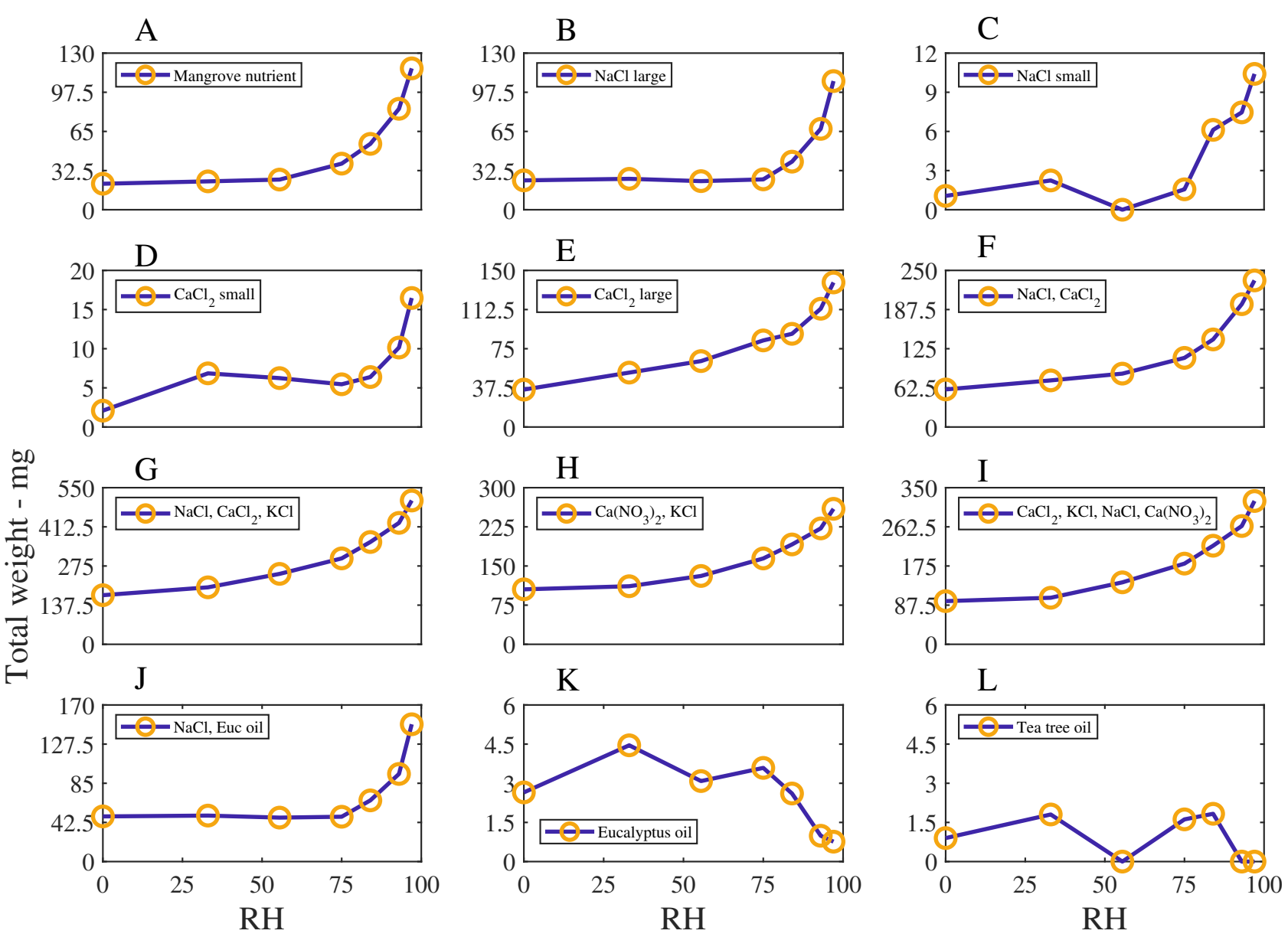

Figure A9: The Total weight (mg) of moisture adsorbed for the controls, with relative humidity, RH (\%). The total weight includes the dry weight and is scaled with the blank. The $y$-axis range changes for each subfigure. 
bioRxiv preprint doi: https://doi.org/10.1101/2021.11.22.469518; this version posted December 14,2021 . The copyright holder for this preprint (which was not certified by peer review) is the author/funder, who has granted bioRxiv a license to display the preprint in perpetuity. It is made available under aCC-BY-NC-ND 4.0 International license.

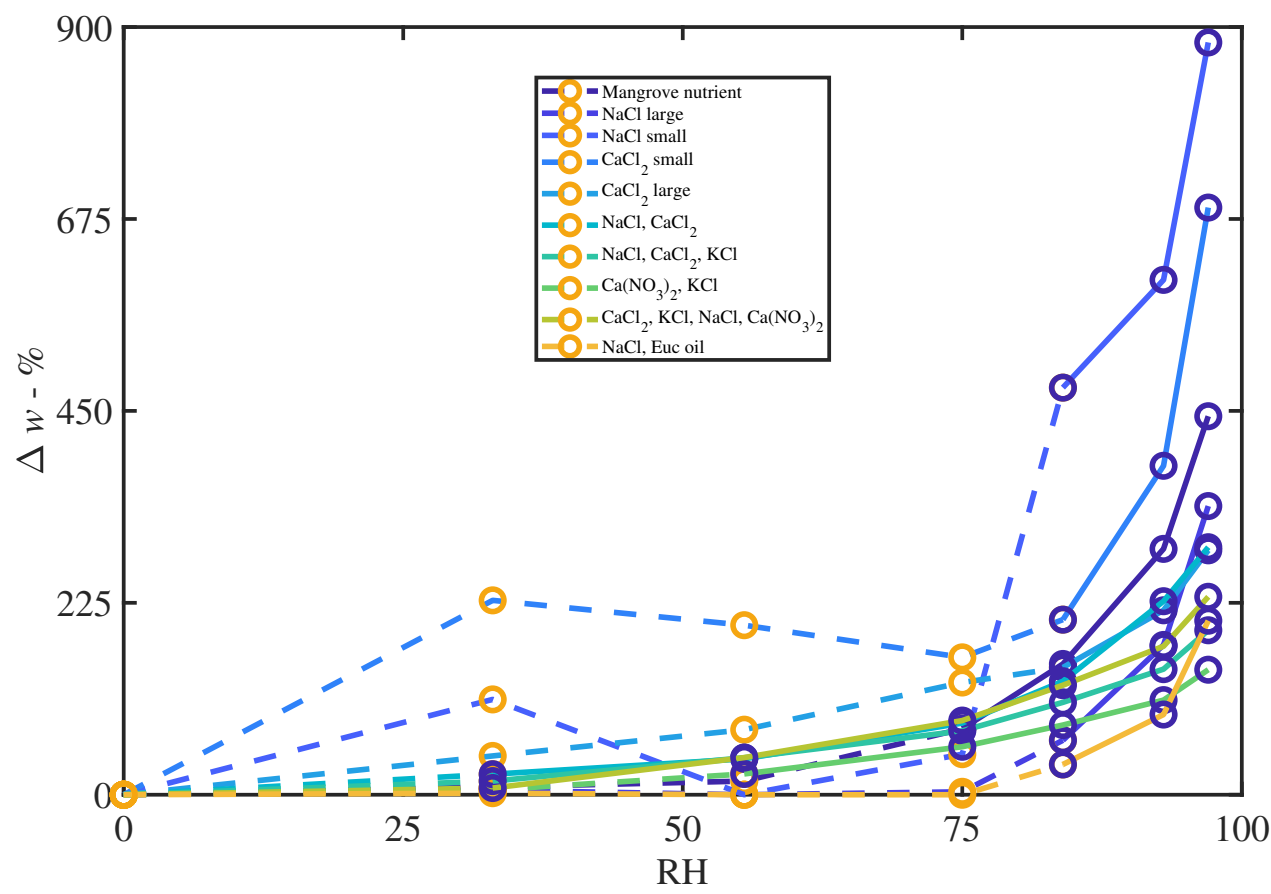

Figure A10: Control samples that have developed a coating of liquid water that is visible without the need for special equipment. The percentage weight increase of moisture adsorbed above the dry weight of the controls, $\Delta w-\%$, with relative humidity, $\mathrm{RH}-\%$, is shown. The orange circles and dashed lines indicate water is not yet visible, and the blue circles and solid lines indicates where liquid water is visible.

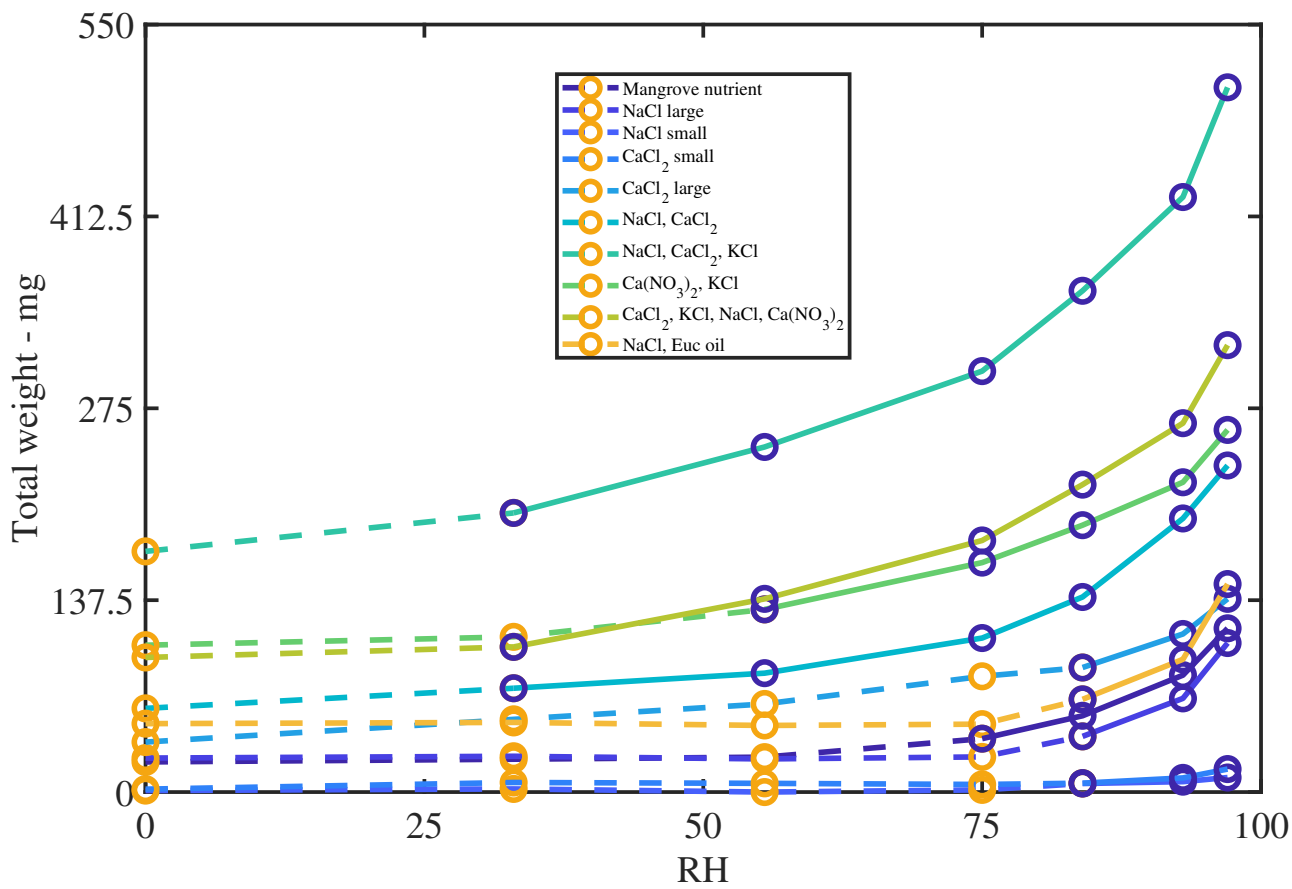

Figure A11: Control samples that have developed a coating of liquid water that is visible without the need for special equipment. The Total weight (mg) of moisture adsorbed for the controls, with relative humidity, RH (\%), is shown. The orange circles and dashed lines indicate water is not yet visible, and the blue circles and solid lines indicates where liquid water is visible. Noteworthy is the significant weight of the $\mathrm{NaCl}+$ $\mathrm{CaCl}_{2}+\mathrm{KCl}$ sample at $97 \% \mathrm{RH}$ of $500 \mathrm{mg}$ or $0.5 \mathrm{~mL}$, although this sample started with the largest dry weight. 
bioRxiv preprint doi: https://doi.org/10.1101/2021.11.22.469518; this version posted December 14, 2021. The copyright holder for this preprint (which was not certified by peer review) is the author/funder, who has granted bioRxiv a license to display the preprint in perpetuity. It is made available under aCC-BY-NC-ND 4.0 International license.

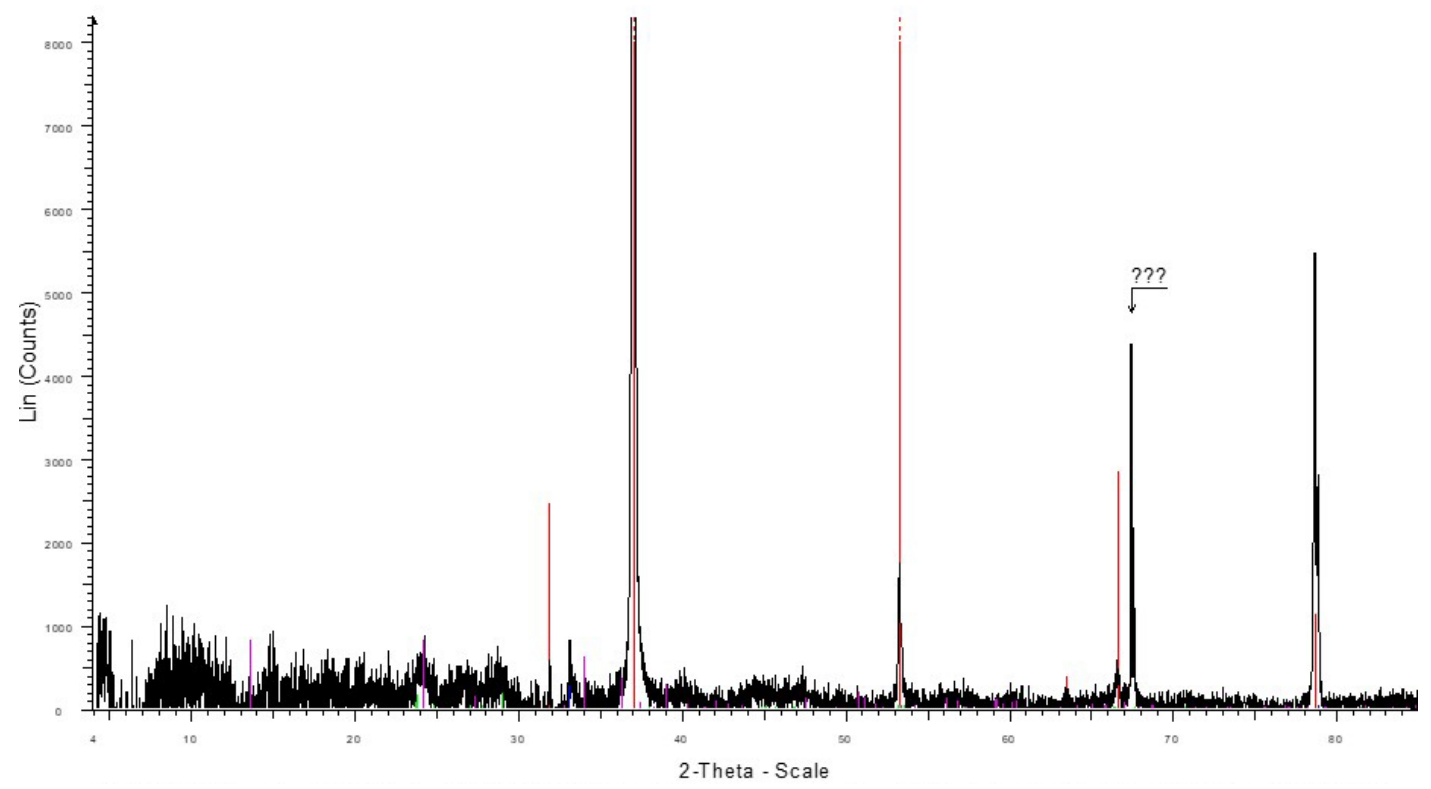

Figure A12: XRD results for Brackish mangrove leaf wash from the liquid wash, and corresponding results are shown in Table 2, with intensity (counts) vs angle (deg 2theta). Red is halite $\mathrm{NaCl}$, blue is sylvite $\mathrm{KCl}$, green is kaolinite $\mathrm{Al}_{2} \mathrm{Si}_{2} \mathrm{O}_{5}(\mathrm{OH})_{4}$ and magenta is gypsum CaSO .

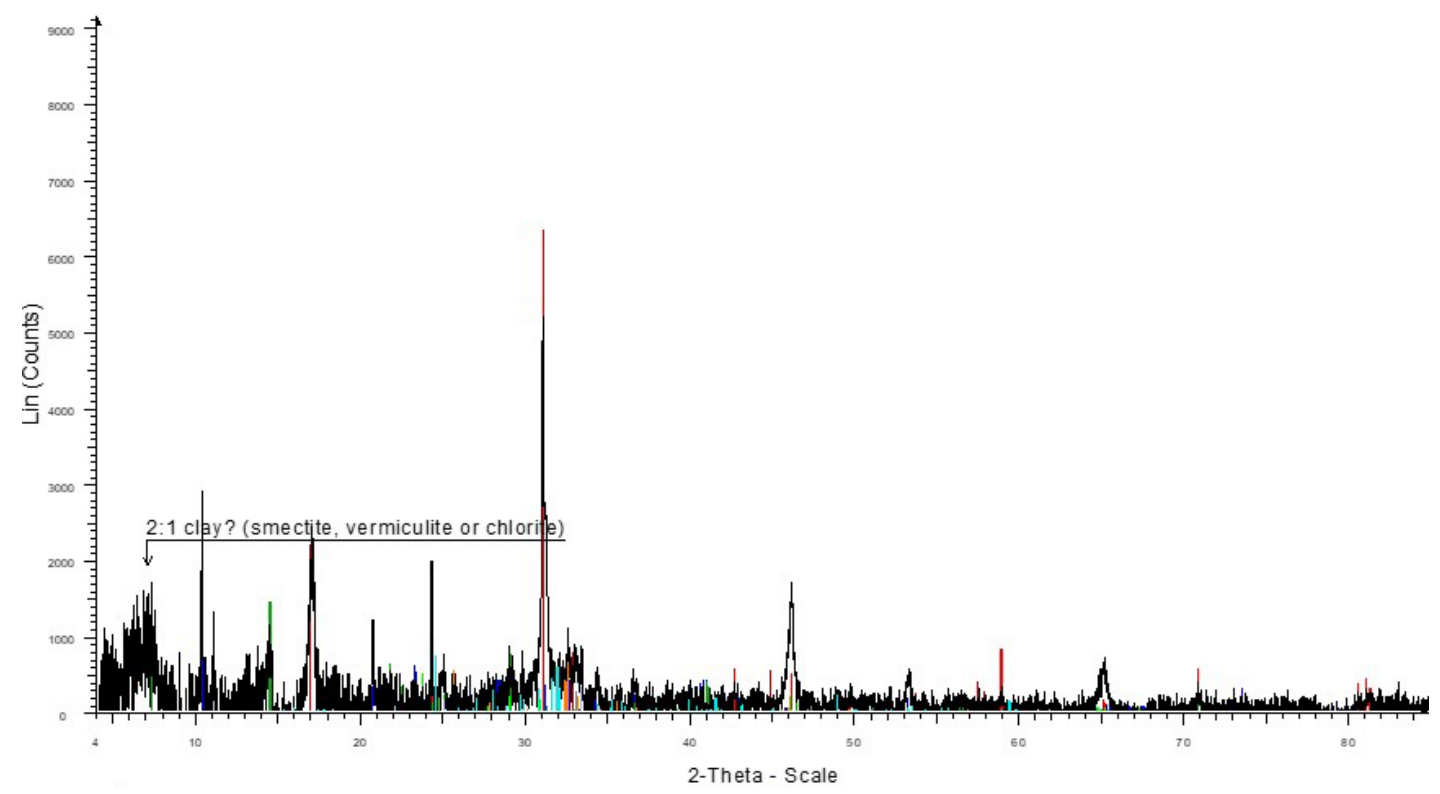

Figure A13: XRD results for Town euc rain leaf wash from the liquid wash, and corresponding results are shown in Table 2, with intensity (counts) vs angle (deg 2theta). Red is quartz $\mathrm{SiO}_{2}$, blue muscovite, light green is kaolinite $\mathrm{Al}_{2} \mathrm{Si}_{2} \mathrm{O}_{5}(\mathrm{OH})_{4}$, dark green is chlorite, orange is plagioclase $(\mathrm{Ca}, \mathrm{Na})_{1-2}(\mathrm{Si}, \mathrm{Al})_{2-3} \mathrm{O}_{8}$, turquoise is $\mathrm{K}$-feldspar $\mathrm{KAlSi}_{3} \mathrm{O}_{8}$, lilac is talc $\mathrm{Mg}_{3}(\mathrm{OH})_{2} \mathrm{Si}_{4} \mathrm{O}_{10}$, grey is sylvite $\mathrm{KCl}$ and dark red is boehmite $\mathrm{AlOOH}$. 
bioRxiv preprint doi: https://doi.org/10.1101/2021.11.22.469518; this version posted December 14, 2021. The copyright holder for this preprint (which was not certified by peer review) is the author/funder, who has granted bioRxiv a license to display the preprint in perpetuity. It is made available under aCC-BY-NC-ND 4.0 International license.

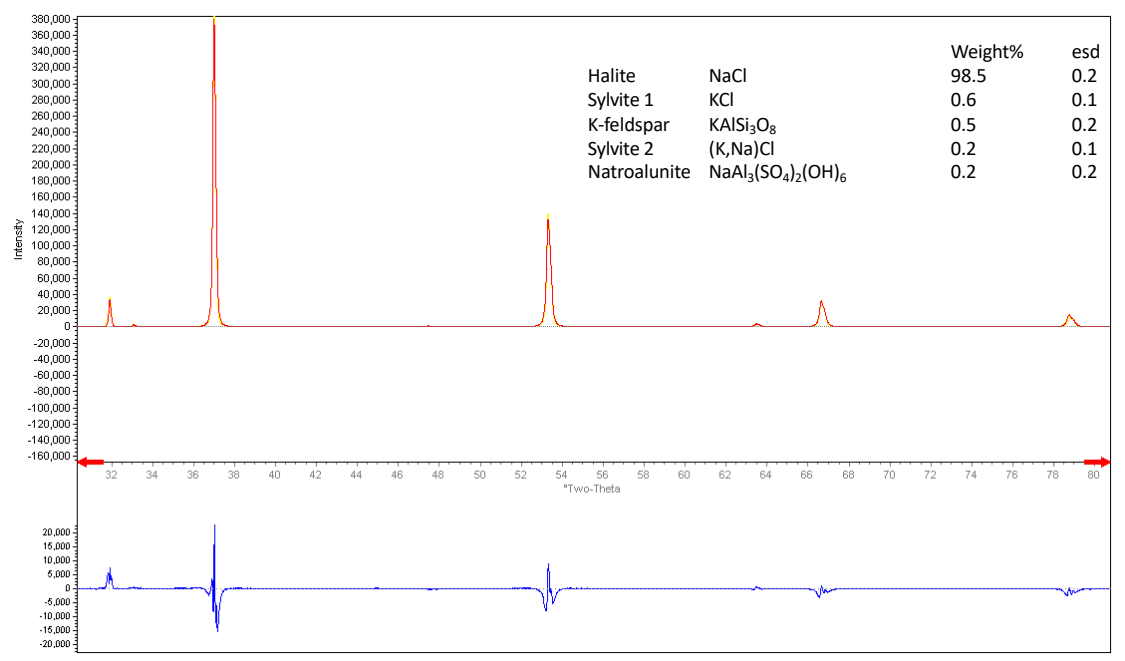

Figure A14: XRD results for a glasshouse mangrove, with intensity (counts) vs angle (deg 2theta). The sample for the XRD was collected by scraping the particles on the bottom of the leaf directly. Note this is the same plant species but a different individual as the Cabinet mangrove sample, and collected at a later date and grown in a glasshouse. No washing of the leaves occurred while the plant was growing.

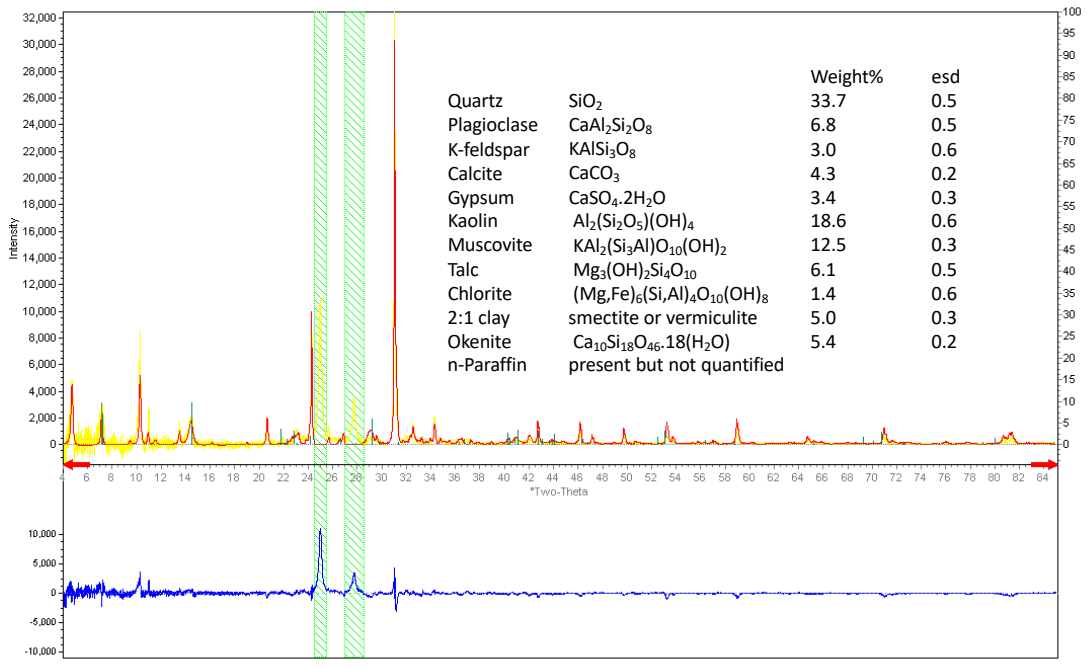

Figure A15: XRD results of Queensland kauri pine (Agathis robusta (syn. A. palmerstonii)), located indoors, with intensity (counts) vs angle (deg 2theta). This species was not included in the original sample set but was located in the same space as the Indoor peace lily. The plant was mature and had very waxy leaves that had a whitish sheen. Several waxes were seen but not quantified (n-Paraffin). The sample for the XRD was collected by scraping the top of the leaf. The bottom scraping shows similar results to the top, and similar to directly onto the leaf, however scraping showed the best results. Analysis was also conducted on the Town euc no rain and lambs ear (Stachys byzantina) with very hairy leaves located next to the town euc, and the results are similar to those shown here. 